SAND- $-90-1719$

SAND90-1719

DE9 1000092

Unlimited Release

printed August 1990

\title{
METAL DETECTOR TECHNOLOGY DATA BASE
}

\author{
Lyle K. Porter, Lawrence R. Gallo, and Dale W. Murray \\ Systems Engineering Division \\ Sandia National Laboratories \\ Albuquerque, NM 87185
}

\begin{abstract}
:
Portal metal detectors are widely used for a variety of purposes. Some of the uses include theft and loss protection, and weapons detection. Although metal detectors are everywhere, the principles of operation and the way in which the machines interact with the objects they are detecting are not understood by a majority of metal detector users. The basic principles of operation are described in this report as well as the results of a series of tests that were designed to illustrate the interaction of detector and target variables.
\end{abstract}


Acknow ledgment

The authors thank D. L. Caskey for his thorough and proficient peer review. 


\section{Contents}

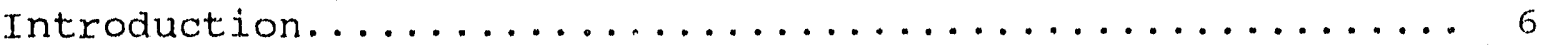

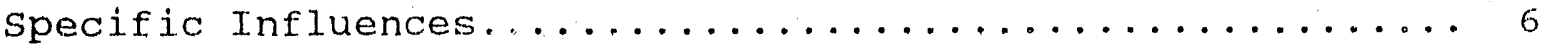

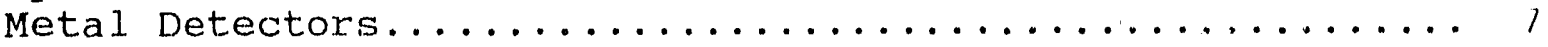

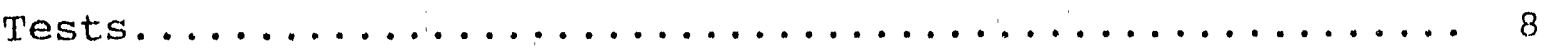

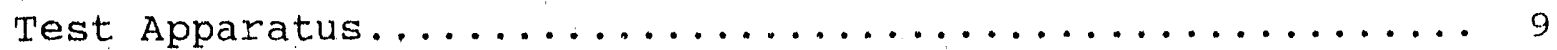

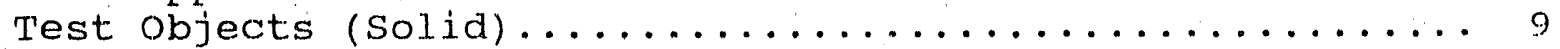

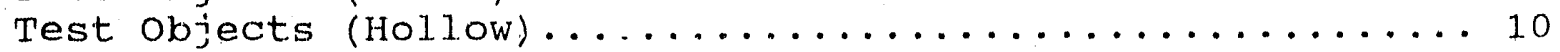

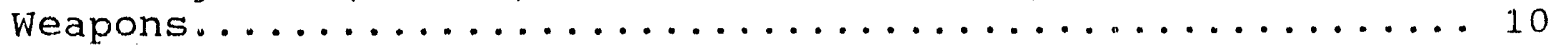

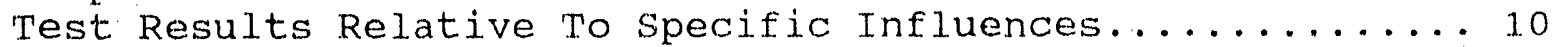

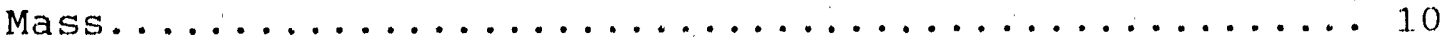

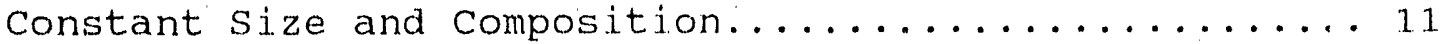

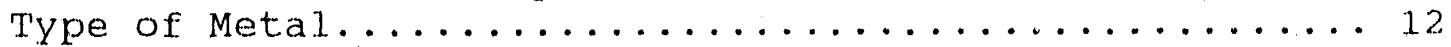

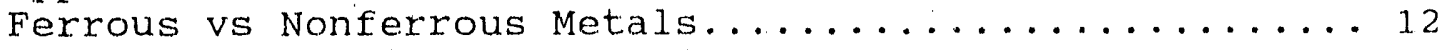

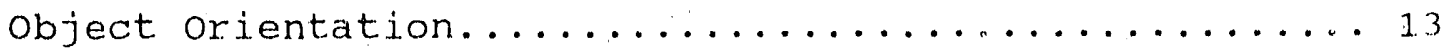

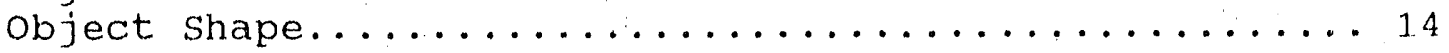

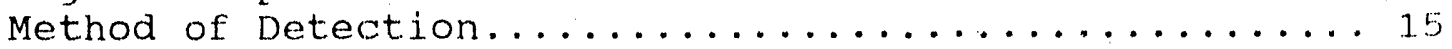

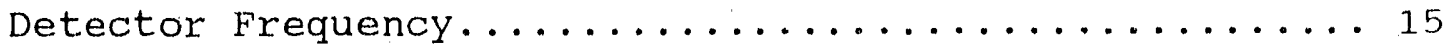

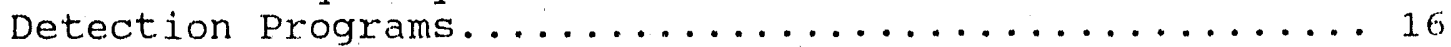

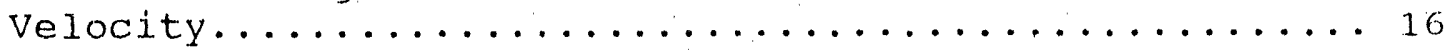

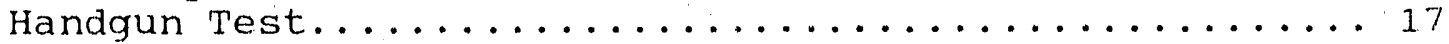

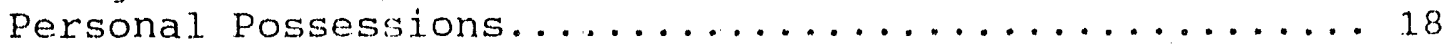

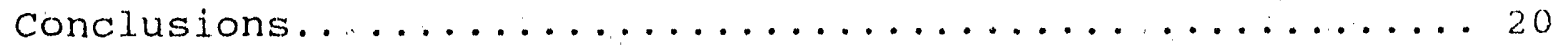

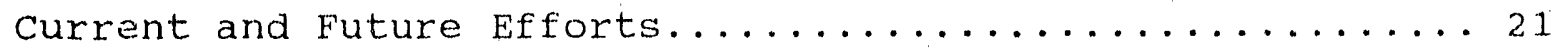

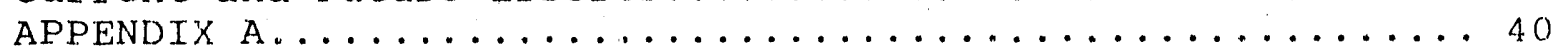

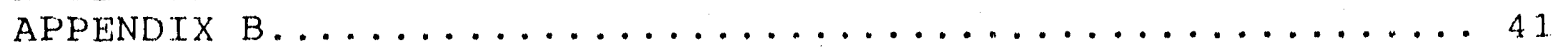

\section{Figures}

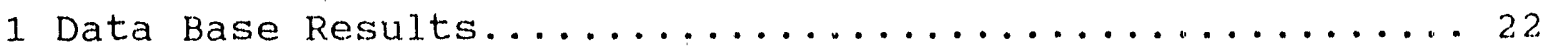

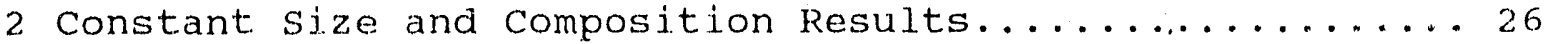

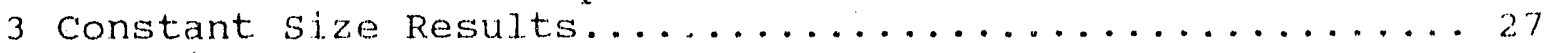

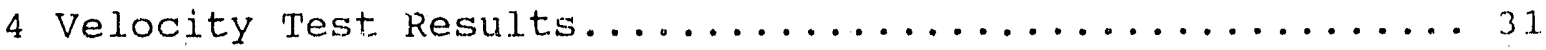

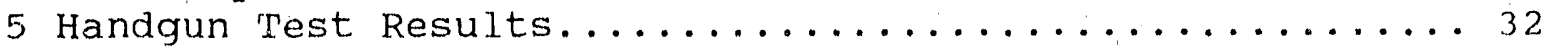

; Personal possession Test Results............... 38

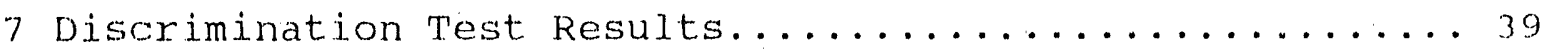

Tables

1 Diameters And Lengths of Test Targets.............. 


\section{METAL DETECTOR TECHNOLOGY DATA BASE}

\section{A. INIRODUCTION:}

The tests described in this report were conducted to obtain information on the effects target characteristics have on portal type metal detector response. A second purpose of the tests was to determine the effect of detector type and settings on the detection of the targets. Although in some cases comparison performance of different types and makes of metal detectors is found herein, that is not the primary purpose of the report. Further, because of the many variables that affect metal detector performance, the information presented can be used only in a general way. The results of these tests can show general trends in metal detection, but do little for making accurate predictions as to metal detector response to a target with a complex shape such as a handgun. The shape of an object and its specific metal content (both type and treatment) can have a significant influence on detection. Thus it should not be surprising that levels of detection for a small $100 \mathrm{~g}$ stainless steel handgun are considerably different than for detection of the $100 \mathrm{~g}$ stainless steel right circular cylinder that was used in these tests.

There are many applications for portal metal detectors. one of the most frequently encountered application is for weapons detection. other uses vary from the detection of nuclear materials and the materials that are used to shield them to protection of kitchen and tool cribs from theft. Because the uses of metal detectors are so widely varied, there is probably no single metal detector that is best suited for all applications. Hopefully, by exploring the strengths and weaknesses of several metal detectors this report may help a metal detector user tc select the machine that is most appropriate for his particular situation.

\section{B. SPECTETC TNFLUENCES:}

Whe tests described in this report are designed to determine the impact of a group of target and detector characteristics on metal detector performance. This group includes the following:

1. 'TARGET CHARACTERTS'TICS

1. Mass of the target

2. Size of the target

3. Type of metal

4. Ferromagnetic vs nonferromagnetic metals 

5. Target orientation
6. Target shape
7. Target velocity

\section{DETECTOR CHARACTERISTICS}

1. Method of detection (pulse vs continuous-wave)

2. Detector frequency (continuous wave)

3. Detector program (pulse type)

Each o: these influences are discussed in more detail later in the report.

\section{METAL DETECTORS:}

The following five metal detectors were used to gather information for this report. A brief description of each follows.

1. Infinetics Friskem-AF', Design 500, Model 1'T1D, 'Type 597D, Series 570, Configuration 1. This particular metal detector was modified specifically to sandia requirements, being provided with four operating frequencies. These include the standard operational frequency of $280 \mathrm{~Hz}$, and $2.2 \mathrm{kHz}, 9.0 \mathrm{kHz}$ and $18.0 \mathrm{kHz}$ as well. Frequencies are selected by changing printed circuit cards.

The Infinetics detector is a continuous-wave system, with balance and gain controls available. It is provided with an occupancy sensor system (transmitter and receiver are switched on only when sensor is occupied), and a digital. readout of signal levels that are designated "ferrous" and "on-ferrous".

2. The Del Norte Sentrie A'I is a pulse type detector. A control panel allows various program changes to be made, as well as changing sensitivity, etc. By the selection w various parameters, a total of eight programs are available, although differences in some cases are silght: The programs of primary interest range from a general. handgun screening program to one designed to detect sinal! stainless steel handguns. There were two ATs used in the testing. The first model was a fixed location interior: portal, while the second AT was a portable weatherproof version.

For alarm display, a series of ten leDs (fight tuitting Diodes) provides information on signal levels. When the signal is sufficient an audible alarm is sounded. 
3. The third detector is the Del Norte Sentrie HS2s. The HSaS is also a pulse type machine, but is not programmalie. The detector does, however, operate in two modes. The first mode is the High sensitivity mode and is intended for detection of small items such as small tools and handguns. While in the High sensitivity mode and at higher gain settings the HS2S. will be prone to numerous alarms due to common pocket cluttex such as coins, keys and pocket knives. The second mode is the Discrimination mode which is intended for detection of larger tools and handguns without the high number of alarms due to pocket clutter.

The alarm display as well as the electronics is housed in a separate control box. Like the AT the HS2S aisplays target response on a ten LED response display. The mode is selected by means of a slide switch, while sensitivity is set using a rotating knob.

4. The fourth detector used is manufactured by outokumpu, a company located in Finland. It is the Metor 118, designed for both indoor and outdoor use. The response display and the electronics are housed in a separate control module. The response display is a series of twelve LEDs. Program selection is performed manually by removing the front cover of the control module and setting four binary switches (for programs o through 15). The gain is set usirig a rotating knob.

5. The final detector is the Outokumpu Metor 120. The electronics for this pulse type detector are housed within the detector aroh, while tre program and sensitivity selection keyboard and the ten LED response display are housed in a small remote box. Like the Metor 118 there are sixteen programs in the latest version; earlier versions had only three programs).

\section{TESTS :}

The first test was performed to establish a data base on detector resporse to a variety of metals and sizes of targets. The results of this data base can then be analyzed with regard to specific influences.

The second test performed was to determine the effect of the mass of the test object on metal detector response while holding target size and type of metal constant.

The third test was ferformed to establish a data base on detector response to small handguns of various shape and composition. 
The fourth test explores the influence of nonsymmetrical target orientation.

The next test measured the detector response as a function of target velocity.

The sixth test was used to determine if target shape will affect detector performance.

The seventh test characterizes metal detector response to a variety of small handguns.

The last test was performed to characterize detector response to innocuous objects that are commonly carried by individuals.

\section{E. TEST APPARATUS:}

The test apparatus consisted of a plastic rail and a plastic container to hold the test object and carry it down the rail. The apparatus, supported at each end by tripods, was positioned to carry the test objects directly through the center of each detector. The velocity of the target through the detector could be varied by changing the size of the drive pulley on the electric drive motor. 'The only metallic object ever within the portal was the test object. In this fashion, both position and velocity are controlled making the tests quite repeatable. While such tests are not directly comparable to walk tests, they do reduce the number of variables to only those that are desired by eliminating the velocity and electromagnetic variability of the walker.

\section{F. TEST OBJECTS (SOLid):}

TABLE' 1

DIAMETERS AND LENGTHS OF RIGHT CIRCULAR CYLTNDERS (DIMENSIONS ARE TN CENTIMETERS)

(DIAMETER EQUALS LENGTH)

$\begin{array}{llllll}\text { Material } & 309 & 709 & 100 \mathrm{~g} & 200 \mathrm{~g} & 300 \mathrm{~g} \\ \text { ALNICO (\#5) } & & & & & \\ \text { Aluminum (20/24 T'4) } & 2.73 & 2.30 & 2.59 & 3.26 & 3.73 \\ \text { Brass } & 2.39 & 3.18 & 3.58 & 4.51 & 5.17 \\ \text { Carbon Steel (1018) } & 1.65 & 2.20 & 2.47 & 3.12 & 3.57 \\ \text { Cast Iron } & 1.69 & 2.25 & 2.53 & 3.19 & 3.65 \\ \text { Lead } & 1.67 & 2.22 & 2.50 & 3.15 & 3.61 \\ \text { Stainless Steel (\#303) } & 1.51 & 2.00 & 2.26 & 2.84 & 3.26 \\ \text { Zinc } & 1.67 & 2.23 & 2.51 & 3.16 & 3.62 \\ & 1.87 & 2.48 & 2.79 & 3.52 & 4.03\end{array}$


The set of solid test objects (test targets) used to obtain the data base is comprised of 40 right circular cylinders. The length and diameters were chosen to be approximately equal. These objects were fabricated from eight different metals, both ferrous and nonferrous, and in 5 different masses (sizes) for each metal. The metals were chosen to be representative of several ferromagnetic and several nonferromagnetic metal.

\section{G. TEST OBJECTS (HOLIOW):}

To obtain information on how detection is affected by size versus mass, two 300 gram aluminum test objects were hollowed out in different amounts. While the outside aimensions remained the same, the masses of the targets were reduced to 224 and 106 grams. Detection tests were then conducted and comparisons made with detection of the solid test objects.

\section{H. WEAPONS :}

\section{DESCRIPTION}

1) Stainless steel minirevolver. 22 Long with 1. 1/8" barrel. Nanufactired by North American Arms

2) Zinc frame automatic pistol. MP-25, 25 cal. ACP. Mfg. by Raven Arms

3) Aluminum frame Mode1. 7 , $.380 \mathrm{cal}$. automatic. Mfg. by American Derringer corp.

4) Al1 arbon steel 3409 Moded "The Best" Mfg. by FIE Corp.
WEIGHT

$128 \mathrm{~g}$

$400 \mathrm{~g}$

$234 \mathrm{~g}$
COMMENTS

Al1 stainless steel except one spring. Steel is cast, $17-4$

About $90 \mathrm{~g}$ is steel. Zinc is Zymac 5 , an alloy with some copper.

Barrel \& frame is aluminum. other parts are stainless steel.

Al 1 parts except grips are made of carbon steel.

\section{TEST RESULTE RELATIVE TO SPECIFIC TNFLUENCES:}

\section{Mass:}

How much of a role does the mass of the target play in metal detector response? Studying the results of the data base 
raw data (figures 1 through 8) does not yield conclusive results. While it is true that increasing the mass of the tirgets seems to increase the detector's response, the size of the target is also changing. To determine which variable (mass or size) is most responsible for the magnitude of the response, some theoretical analysis as well as some more testing must be performed.

In the case of the pulse detectors, the magnitude of the response is directly proportional to the magnitude of the eddy currents that develop in the targets as they pass through the detector arch. One of the major causes of perturbations in tie field of the continuous wave detectors is from field losses due to eddy currents. This means that whichever factors most impact eddy current magnitude are the factors that most impact metal detector response. T're magnitude of the eddy current is dependent on several factors. First, the velocity of the target is important because it determines the rate trat the target cuts through lines of magnetic flux. For the data base tests the velocity of the targets is held constant and in this case is not a variable factor. The second factor is the surface area that is normal to the lines of magnetic flux. This implies that shape and size play important roles. The final factor that plays a role is skin depth.

Skin depth is defined as the thickness of a conductive material that contains $63.2 \%$ of the electromagnetic field that penetrates the surface. As the field progresses into the material, it is attenuated such that at a thickness of five skin depths the field is essentially zero (in other words approximately $100 \%$ of the field is contained within five skin depths). If the target is thin (one or less skin depths thick) then not all of the field energy is used to create eddy currents. Target thickness will have a major impact on eddy current magnitude. Skin depth is invers $l$ proportional to field frequency, the permeability of the material and the conductivity of the material. Field frequenoy is machine dependent and within test groups is held constant. The reflectivity, the permeability and the conductivity are all material dependent. This indicates that the only target dependent factors influencing eddy current magnitude are target geometry and target composition.

\section{Constant size and composition:}

To test this theory, a set of hollow targets was run through the detectors. Because the wall thicknesses of the hollow targets are less than several skin depths for the lower frequency components of the field, there should be some drop of the detectors' response, but: it should not be dramatic (as is the case when the overall size of the target decreases as the 
mass decreases). Figures 9 through 11 show the comparison results of these tests. As expected, there is little decrease in detector response as the mass decreases while the outside dimensions are held constant.

\section{T'ype of Metal:}

Taking into account the fact that the dimensions of the target are more important than the actual mass of the target, the raw data can be organized to show the effects of target composition while size is held constant. Choosing the $70 \mathrm{~g}$ aluminum cylinder, the $300 \mathrm{~g}$ lead oylinder and the 2009 cylinders for the other metals allows a reasonable comparison between targets of neamly the same dimensions. Mean target sae is $3.23 \mathrm{~cm}$ (length and diameter) with a standard deviation of $0.130 \mathrm{~cm}$. The largest target was the zinc at $3.52 \mathrm{~cm}$ and the smallest target. was prass at $3.120 \mathrm{~m}$. Figures 12 through 19 show the results of this comparison.

4. Ferrous ve Ncriferrous Metalis:

Acain looking at the graphs of the constant size comparison (Eigures 12 through 19), one can see a trend in detector response with respect to the furromanetio characteristics of each metal. 'Lhe ferromarnetic metals (carbon steel, cast iron, and AbNTCO) produce a higher response than the nonferromagnetic metals. This is also the case with the outokumpu Metor 118 and the fneinetios machines. This is not the case, however, with the Del Norte Sentrie AT. The A'l can be programmed to favor either ferromangetic or nonferromagnetic metals (this will be discussed further in the section on detector programs). The mportant point about bel Noxte AT response to ferromagnetic and nonferromagnetio metals is not which produces the greater rosponse, but this the two types of metals are discornibie.

For many years people have talked about ferrous and morerros metals in association with metal detectors. The Infinetics metal deteutor used tor some of the tests has a dual digital readout of signal levels; one for ferrous, one for nonferrous. Whe data presented in this report uses that furmet. Past "istandards and crites ia for bot Inspections and fraluntions" have specified that $100 \mathrm{~g}$ masses of "ferrous and ronterrous metal" be used for detecton criteria. The implifation of these and other statements is that there is some thing impotal about the ferrous inonferrous terminology. Actually, when doscribing the eloctromagnetio nature of a metal the term ferromanetic is moro suitable than the chemical term terrows. The nonterrous alloy Alwa contains no iron while the stainless ateel alloy contains uniefly iron; yet the magnetio ArNCO aliats a response in the metal dotectors that more closely matches ferromagnets response than does the terrous stainhess steel. 
These readings are not inconsistent. The AlinICO alloy is a magnetic metal (ALNICO is commonly used to fabricate permantint magnets). The stainless steel test objects (cylinders) are made of an austenitic alloy of steel, and is nonferromagnetio (it is not attracted by a magnet). other types of stainless steel are martensitic (the .22 mini-revolver is made of martensitic stainless steel which is a magnetic alloy), and behave like ferromagnetio metals in a metal detector. Thus, the proportion and type of added noniron metals, plus the hardening process, affect the characteristics of the steel in ways that also affect metal detector performance.

The best conductors of the nonferromagnetic metals have a considerably higher conductivity than the best conductors of the ferromagnetic metals. This fact alone would suggest that the high conductivity nonferromagnetic metals would be more easily detected than the ferromagnetic metals; however, this is not the case. Why then do some of the ferromagnetic metals elicit a greater response than do many of the better conducting nonferromagnetic metals? The answer lies in the fact that the relative permeability of the ferromagnetic metals is typically several orders of magnitude greater than the nonferromagnetic metals. Nonferromagnetic metals have a relative permeability of one, the same as vacuum. These metals have no ability to distort the magnetic field as do the ferromagnetic metals. While the field that enters a nonferromagnetic metal is simply the field that is incident on the surface of the metal. Ferromagnetic metals, on the other hand, distort the magnetic field by attracting magnetic lines of flux such that the field passing through the metal has a higher flux density than the undistorted field. If the field strength is sufficiently higher in the ferromagnetic metals to compensate for the lower conductivity, the ferromagnetic metal will be as detectable as the better conducting nonferromagnetic metal.

\section{Object orientation:}

To test for the influence of object orientation, a three inch square of $1 / 16$ plate aluminum was passed through the detection arch of a Del Norte A'T and the infinetics detectors (one pulse and one continuous wave) in the vertical orientation (the large flat surfaces of the plate were parallel to the walls of the detector arch). The plate was then passed through the arches in the horizontal orientation (the large flat surfaces of the plate were parallel to the floor). The results were that the response of the detectors was substantially greater when the plate was in the vertical orientation than in the horizontal orientation. Wher the Del. Norte AT was running program one, with a gain or sensitivity setting of twenty, the response was eight lights for the vertical and no response (zero lights) for the horizontal. The Infinetics machine 
operating at $230 \mathrm{~Hz}$ followed the same pattern. The vertical response was $0.025 \mathrm{mV}$ (ferrous) and $0.049 \mathrm{mV}$ (nonferrous). The horizontal response was $0.014 \mathrm{mV}$ (ferrous) and $0.013 \mathrm{mV}$ (nonferrous); this was not distinguishable from the ambient (no metal in the arch) response which was $0.009 \mathrm{mV}$ (ferrous) and 0.013 (ronferrous).

The explanation for this orientation phenomenon is that in the vertical orientation the large flat surfaces of the plate are essentially normal to the magnetic field. This means that maximum eddy current is achieved when the plate is in this orientation. When the plate is paraliel with the floor, the surfaces are tangent to the magnetic flux lines and eddy currents are minimized.

6. Dbject shape:

To determine the effect of shape on detector response, the square plate of the previous test was used in conjunction with a rectangular plate made from the same aluminum stock. The rectangular plate was one inch wide by nine inches long so that both plates had the same areas (nine square inches) and thicknesses. Again the Del Norte AT and the Infinetics detectors were used. Both machines were set-up in the same configurations as the previous test. The plates were passed through the detectors in the vertical orientation. In the case of the rectangular plate, the long axis was parallel to the flooi. The other vertical orientation for the rectangular plate (long axis upright) was also tested with nearly identical results. The results were that the square plate produced an eight light response, while the rectangular plate produced only two lights. In the Infinetics machine the square plate produced $0.025 \mathrm{mV}$ (ferrous) and $0.049 \mathrm{mV}$ (nonferrous) while the rectangular plate produced only $0.008 \mathrm{mV}$ (ferrous) and $0.018 \mathrm{mV}$ (nonferrous) again barely discernible above ambient.

The explanation for these results has to do with the path lengths of the eddy current loops in the two plates. Because the area (and therefore the encircled magnetic lines of flux) of the three inch square plate is equal to the area of the nine by one inch plate, the induced electromotive force (voltage) is equal. However, assuming the eddy current can follow a rectangular path around the perimeters of the plates, the path around the nine by one inch plate is larger than the path around the three inch square plate. since the electrical path langth of the nine by one inch plate is longer than the twelve inch long loop of the square plate, the resistance will also be greater. By ohm's law, the magnitude of the eddy current in the square plate will be larger than the eddy current of the rectangular plate. For a given surface area, the shape that has the least distarice around its perimeter will produce the 
greatest eddy current (a fact well known to manufacturers of motor and transformer cores).

\section{Method of Detection:}

originallv, most walk-through (portal) metal detectors utilized a continuous wave balanced magnetic field. The presence of metal was determined by the unbalance of that field. One of the difficulties of this approach was that outside interference and nearby moving metallic objects (doors, etc.) also upset the balance of the field, causing unwanted alarms. There were several approaches to solving these problems. The Infinetics machine used in these tests is equipped with an infrared sensor to detect when a person is inside the arch; this greatly reduces the time during which the detector is subject to electromagnetically induced false alarms. Other approaches to solving these problems led to the development of other detection methods, such as dual frequencies and the use of pulsed fields for detection.

Following the successful introduction of the pulsed field method, most portal metal detectors now utilize this technique. In this method of detection, one side of the arch contains a transmitting coil or coils, and the other a receiving coil. The procedure is to turn on the transmitter for a brief period of time (typical pulse lengths are a few tens of milliseconds), saturating any metal within the arch and causing eddy currents to kuild up within the target. The transmitter is then turned off, and after a brief pause (as little as a few microseconds up to a few tens of microseconds), the receiver is turned on. This means that the receiver is only on after the transmitted field has been turned off, and is on during the time the eddy currents within the metal are decaying. It is the measurement of those eddy currents that provides detection. Though there are some disadvantages to this method, the primary advantages are that balancing is not required and, since the receiver is on for only short periods of time (receiver on time duty cycle is far less than 50\%) there is potentially less chance for interference.

\section{Detector Frequency:}

Whether referring to the frequency of a continuous wave field or the frequency components of a pulsed field, these parameters can have a significant effect on detection.

The Infinetics detector used in these tests was purchased with a modified capability to select any one of four frequencies. The tests results shown in figures 1 through 4 show that increasing the field frequency increases detector response, at least through $18.0 \mathrm{kHz}$. NOTE THE MILLIVOLT SCALE 
CHANGE FROM FIGURE TO FIGURE! In addition, due to the large signal available, the gain of amplifiers used for frequency "D" is one-half that or the other three frequencies. This means that while signal levels for frequency "C" \& "D" appear to be about the same in the plots, in reality, signal levels for frequency "D" are double those for "C". The only unfortunate thing about increasing frequency for detection of contraband items, for example, is that all items, including personal possessions are also detected more easily.

The most dominant factor causing this behavior is again skin depth. Since skin depth is inversely proportional to frequency the skin depth is less for the higher frequencies. With shallow skin depth more of the incident field energy is converted to eddy currents causing a greater field perturbation.

\section{Detection Programs:}

In the case of pulse-type detectors, pulse rate, spacing, etc., can have a similar, but more complex, effect on detection than changing frequencies for the continuous wave detector. Figures 14 and 15 clearly show the detection variations existing for two of the programs running on the Del Norte sentrie AT. By changing the delay between when the transmitted pulse ends and when the time that the receiver is switched on, the AT can be adjusted to have a higher response to either ferromagnetic or nonferromagnetic metal. Program four clearly produces a much higher response to ferromagnetic metals while program one produces a higher response to the nonferromagnetic metals.

other characteristics that can be influenced by programs are noise filtering, response versus target velocity, and the machine's ability to discriminate between a single large item and several smaller ones. For listings of program parameters for the Del Norte Sentrie AT and the outokumpu Metor 1.18 see Appendices $A$ and $B$.

\section{Velocity:}

Figures 20 and 21 indicate differences in detection due to velocity. The standard velocity is considered to be $1.1 \mathrm{~m} / \mathrm{s}$, with $0.45 \mathrm{~m} / \mathrm{s}$ and $1.8 \mathrm{~m} / \mathrm{s}$ respectively the lower and upper boundaries of the normal operational range for metal detectors. As one can see, the detection for the machines tends to decrease at one or both of the extremes of the operational velocities. Manufacturers' data indicate that detection is nearly flat in the regions between the extremes with a fairly sharp roll-off at the extremes. For the pulse machines the 
detection at and even beyond the extremes can be enhanced by program selection.

\section{Hand Gun Test:}

This test was intended as a real-world point of reference for the other tests, since handguns are often the targets of portal detectors in actual security applications. Since the guns chosen (see section $H$ ) represent both a wide variety of: materials and the smallest guns currently on the market, they were a logical choice for this test. Each gun is composed predominantly of one type of metal, and it is important to point out that there are several guns on today's market that. are composed of multiple types of metals. The composite guns can even further complicate detection due to the dissimilar metal cancellation phenomcnon discussed in the personal possession section.

The results of the gun detection tests are presented in figures 22 through 32 . The data shown in these graphs are in a different format than the data in the other graphs. Rather than displaying detector response on the vertical axis, the percent required sensitivity setting is shown. The lowermost section of the bar represents the sensitivity setting range that the detector did not detect or detected unreliably. Above the lowermost section is the the range of sensitivity settings at which the detector would detect five out of five passes. The threshold between no detection and detection was quite distinct and repeatable. The uppermost area of the bar (if present) represents sensitivity levels that causeci the detector to go into constant or frequent alarms, at least to the point that real alarms could not be distinguished from false alarms.

At first inspection it is difficult to detect any trends to the detection patterns. One general pattern that emerges is that the ferromagnetic versus nonferromagnetic detection pattern exhibited by the Del Norte sentrie AT in the constant size tests is still apparent in the results of the gun tests. This trend is most apparent in figures 22 and 24 . Two additional prograns for the Del Norte AT (program three shown in figure 2.3, and program five shown in figure 25) were included in this test because they are better suited for small weapons detection. The ferromagnetic versus nonferromagnetic behavior is masked in the case of the outokumpu Metor 118 due to the level of sensitivity required to detect the stainlesis steel .22 cal mini-revolver (the stainless steel alloy used to make this gun is a ferromagnetic alloy). The most obvious reason for the high level required for this gun is its especially small size. This again is also true for the Infinetics Friskem 570. The trend is evidenced only by the fact that the most detectable weapon is the $.25 \mathrm{cal}$ pistol "The 
Best". It is difficult to determine the role played by the shape of the weapons, but shape surely has some influence on detection.

\section{Personal Possessions:}

Figure 33 is data taken from the Infinetics detector at $280 \mathrm{~Hz}$, the standard frequency for this machine. This test was conducted by sending all of the personal possessions listed along the abscissae through the arch. Then prior to each subsequent pass a single item was removed until the last pass where a single item remained. It is interesting to note that. that detector response does not necessarily decrease when an additional item is removed; in some cases detector response increased.

The decaying eddy currents that follow the transmitted pulse are an alternating signal that looks very much like a heavily damped sinusoid. The signals that are produced by two dissimilar metals differ not only in absolute magnitude but also in sign at various times during the life of the signals. Thus, two dissinilar metals (especially a ferromagnetic and a nonferromagnetic) can produce eddy currents that differ in sign such that the point by point algebraic sum of the two signals during tne time that the receiver is enabled can partially carcel eich other. This means that, for example, the removal of a ferromagnetic item from a group of nonferromagnetic items can cause the overall signal to increase.

The right side of the graph contains information from the cylindrical test targets and several small weapors for reference. Note that in sorne cases an alarm would occur from the possessions as easily as from a weapon or weapon sized object.

The data shown in figure 34 shows just how varied the response can be for one type of item. This test involved ten different belt buckles; each was passed through the detector arch five times. It is clear that if one talks about metal detector response with respect to personal possessions, it is necessary to define the possessions in great detail.

A second series of personal possession tests were run to determine the discrimination abilities of the varinus machines as well as to tie together the results of the handgur test with the results of the personal possession test. With respect to metal detector behavior, discrimination is defined as the detector's ability to distinguish between the intended target and incidental pocket clutter. The machines chiefly rely on their ability to discern the difference between a single large item and a collection of smaller items even though the 
accumulative size of the clutter may be as large or even larger than the actual target.

To perform this test, the mechanical test track was replaced by a human walk tester. The machines were adjusted to detect all four guns in several body positions. The three body positions were the top of the head, the waist, and the ankle. A human tester was selected to reintroduce all the variations that would normally be encountered in the field. A sensitivity setting was found that would detect all weapons in all body positions five times out of five passes. This minimum sensitivity can be considered to be the optimum setting since the nuisance alarm rate should by as low as possible and still allow reliable detection. The choice of the programs tested was determined by two criteria. First, the chosen program was suggested by the manufacturer as appropriate for small handgun detection. Secondly, only programs that would detect all four of the test weapons were tested.

After adjusting the detectors, a clean tester began making passes through the detector arch carrying a collection uf pocket clutter. A clean tester is defined as someone whose clothing is devoid of metal and whose body contains no significant metaliic objects (such as surgical implants or extensive dental work). The pocket clutter consisted of a large pocket knife, a cigarette lighter (plastic butane with a steel flame guard, an $x$-acto knife (aluminum handle with steel blade), a steel key ring with three keys (one aluminum and two brass), a digital wrist watch with a nonmagnetic stainless steel back, a collection of change (one quarter, four dimes, and five nickels), and a small brass belt buckle. If the detector alarmed, the items were removed one at a time in the order listed; following the removal of each item a pass through the detector was made. This process was continued until the detector no longer alarmed.

The results of the pocket clutter discrimination test are presented in figure 35. An "A" in a column indicates that an alarm occurred when the item in that row was carried along with all the other items listed below it. A "p" in a column indicates the item in that row and all the other items listed below it can be carried through the detection arch with no alarm. A dashed line separates the items that cause alarms from the items that can pass. The results show that for this particular collection of items, the Del Norte AT running program five has the highest tolerance for pocket clutter. simply removing the large pocket knife from the collection allowed the tester to carry the remaining items through the detector. 


\section{J. CONCLUSIONS :}

These tests show sume general trends in metal detector response to various test targets and under several sets of configurations. They also reveal the complexity of the factors that impact detector performance, even under the controlled conditions of these tests. To predict a metal detector's response to any thing other than a very simple target (one of: simple shape and composed of a single melal) is at best an extremely difficult task.

Some general observations that can be made are: The more narrowly one can define the contraband to be detectea, the better will be the detection and the lower the nuisance alarm rate. If the spectrum of contraband is wide, then to effectively adjust the detector the set of items used to test the detector should reflect that wide spectrum, and should be realistic (if one intends to detect guns then the test set should be comprised of several guns made of a variety of metals arid of various sizes and shapes). With the complex array of factors that influence metal detector response, it is highly unlikely that any single test object can be found or even devised that will adequately test a metal detector.

The results of these tests can give the reacer some guidance as to choosing the best metal detector for a given application. If the application is to detect large metal objects (large handtools ect.), the selection is quite simple; choose a metal. detector that is inexpensive. Most any modern metal detector can detect large items with a minimal amount of nuisance alarms. If, on the other hand, the application is to detect smaller items made of a variety of metal types, the newer digital machines exhibit a much better combination of sonsitivity and discrimination. Another area where the digital technology excels is the ability to target specific metal types. A good example of the flexibility of the digital technology is the Del Norte AT with its ability to very clearly distinguish between ferrous and nonferrous metals and its ability to detect the very small. North American Arms minirevolver while still allowing a tester to carry a wide variety of pocket clutter items.

In general, selecting a metal detector for most applications is no simple task. The same is true when devising a test procedure and choosing a set of test objects. In order to make the best choices, one should know as nuch as possible about the specific application; one should clearly define the threat. Also, one should understand the abilities and linitations of the metal detectors under consideration. 


\section{K. CURRENT AND FUTURE EFFORTS:}

The work described in this report is part of a continuing project at Sandia National Laboratories. The testing continues in an effort to better understand the process of metal detection in order to develop better operational performance testing and to improve the technology. In addition, research is being considered to investigate new methods of detection.

Currently, the major thrust of the testing is collecting variables lata on the ef ects of various persons on metal detection. This testing is being conducted to allow statistica? analysis of the data in order to develop a new approach to operational performance testing. The current method of testing involves making numerous passes through the detector to verify the probability of detection at some specified confidence level. Depending on the magitude of the required probability of detection and confidence level, the required number of passes can be very manpower intensive, especially at a facility which has numerous detectors. Because the output of the detector is binary (detect or no detect) the required number of data points is quite large. By bringlng the analog response signal out of the machine, variables data (response magnitude) can be collected. Once the machine has been certified to have a given probability of detection at a specified confidence level, this new approach of variables testing will allow the verification of the continued performance level with far fewer passes.

other work that will begin soon is to transfer information to industry to assist them in their efforts to provide better detectors. One of the enhancements that could have an immediate impact would be providing a variables data readout to simplify the performance testing. Since current detector programs exhibit a higher sensitivity for a single type of: metal (ferromagnetic or nonferromagnetic), another possible change could be composite programs for broad spertrum detection.

one result of this study is that it is apparent that conventional metal detection has its limitations. Whether operating independently or in conjunction with conventional metal detectors, new technologies are needed to counter the increased threat of smaller weapons and the increase in the use of nonmetallic materials in handgun construction. one such technology that shows promise is millimeter wave imaging. This technology and others are being considered tor future research projects. 


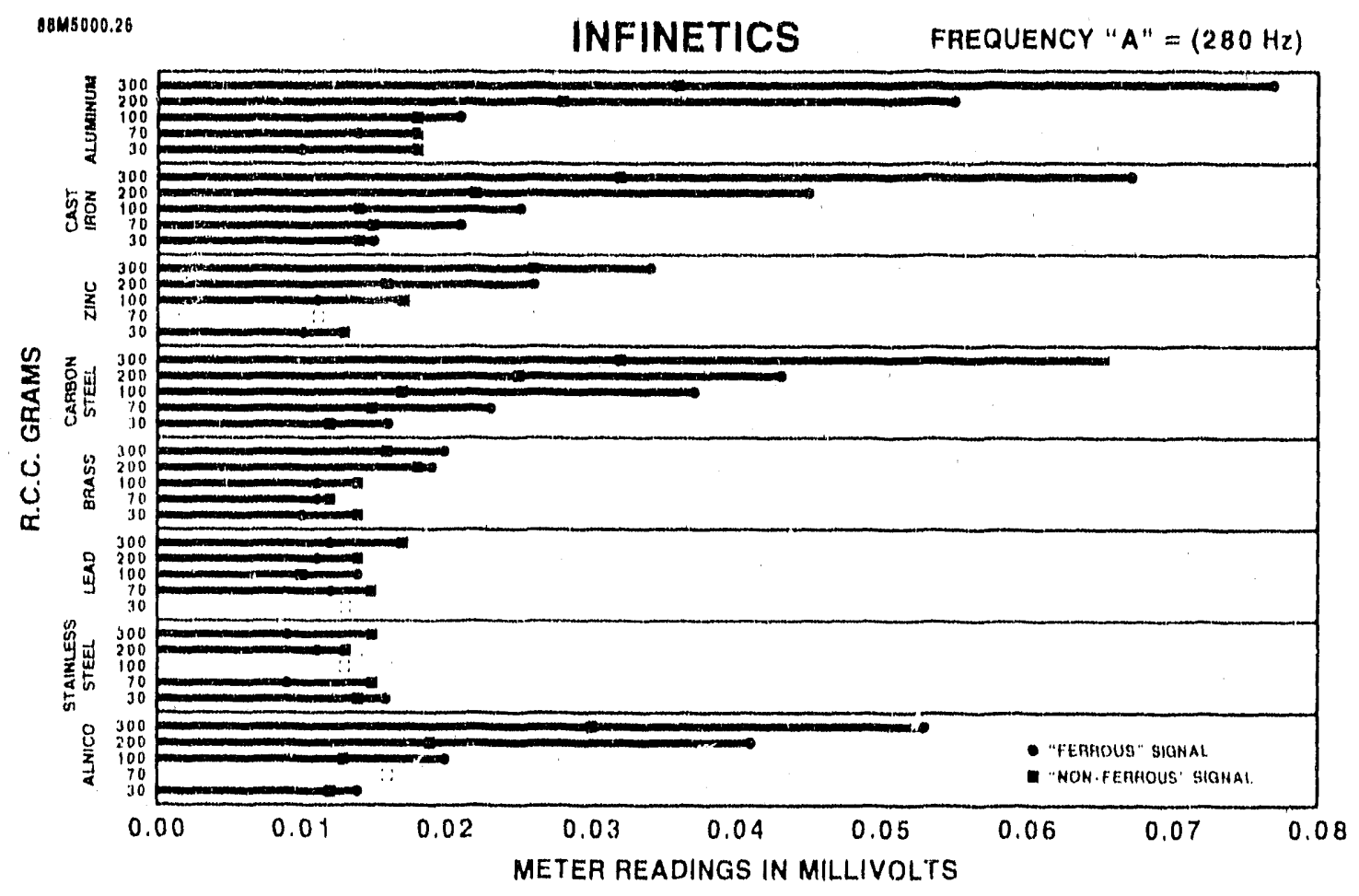

Figure 1-1

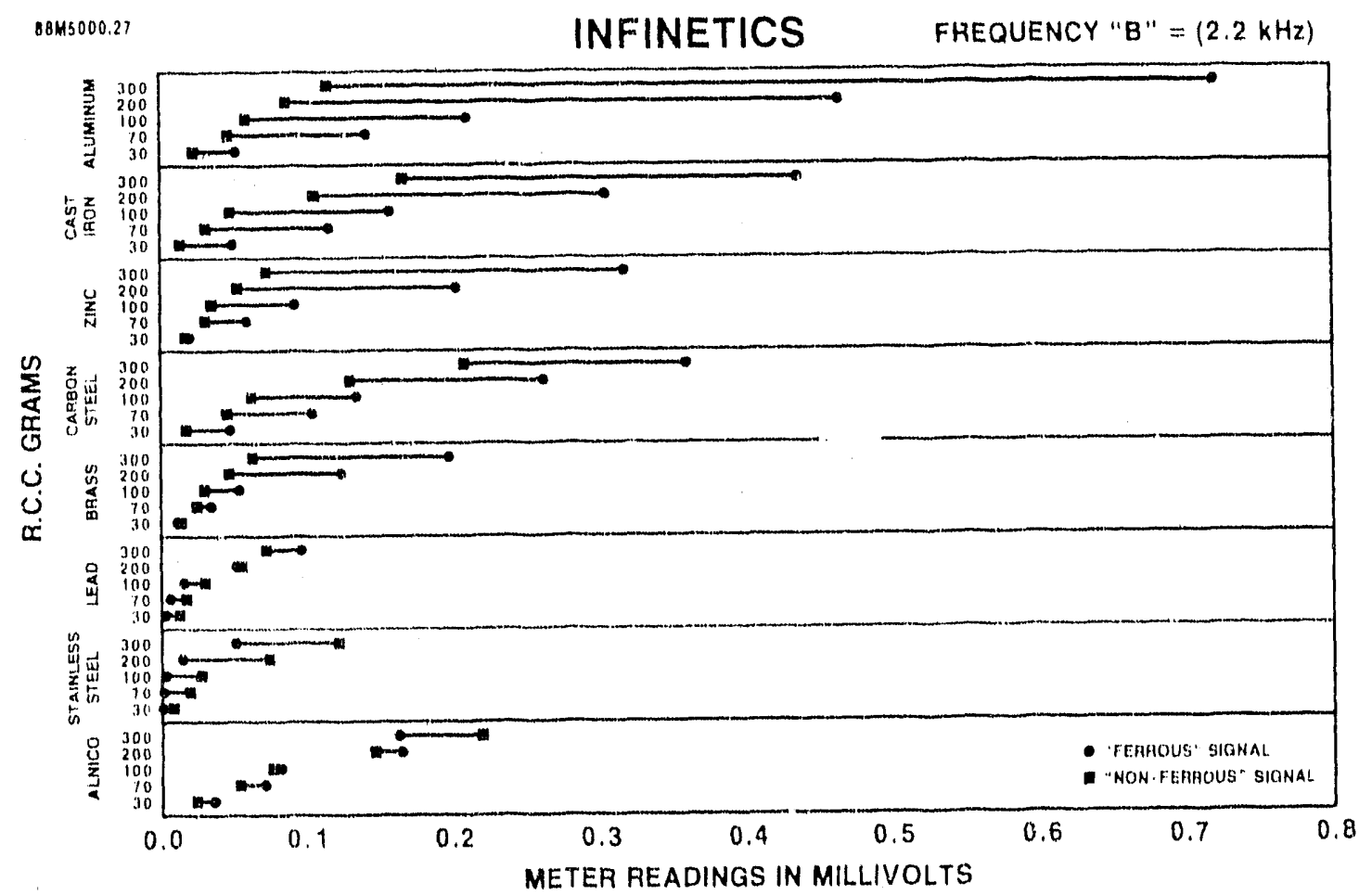

Figure $1-2$ 


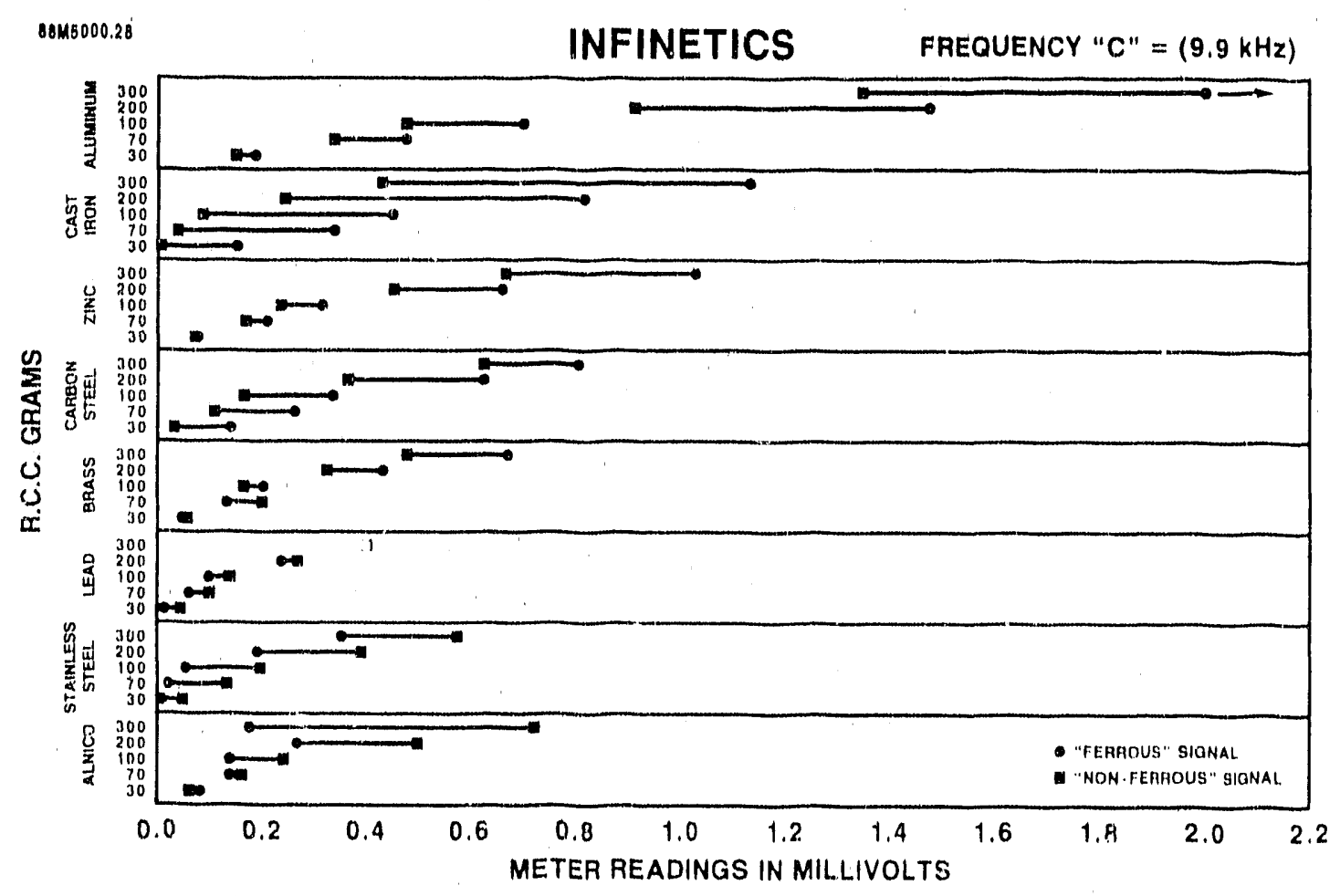

Figure 1-3

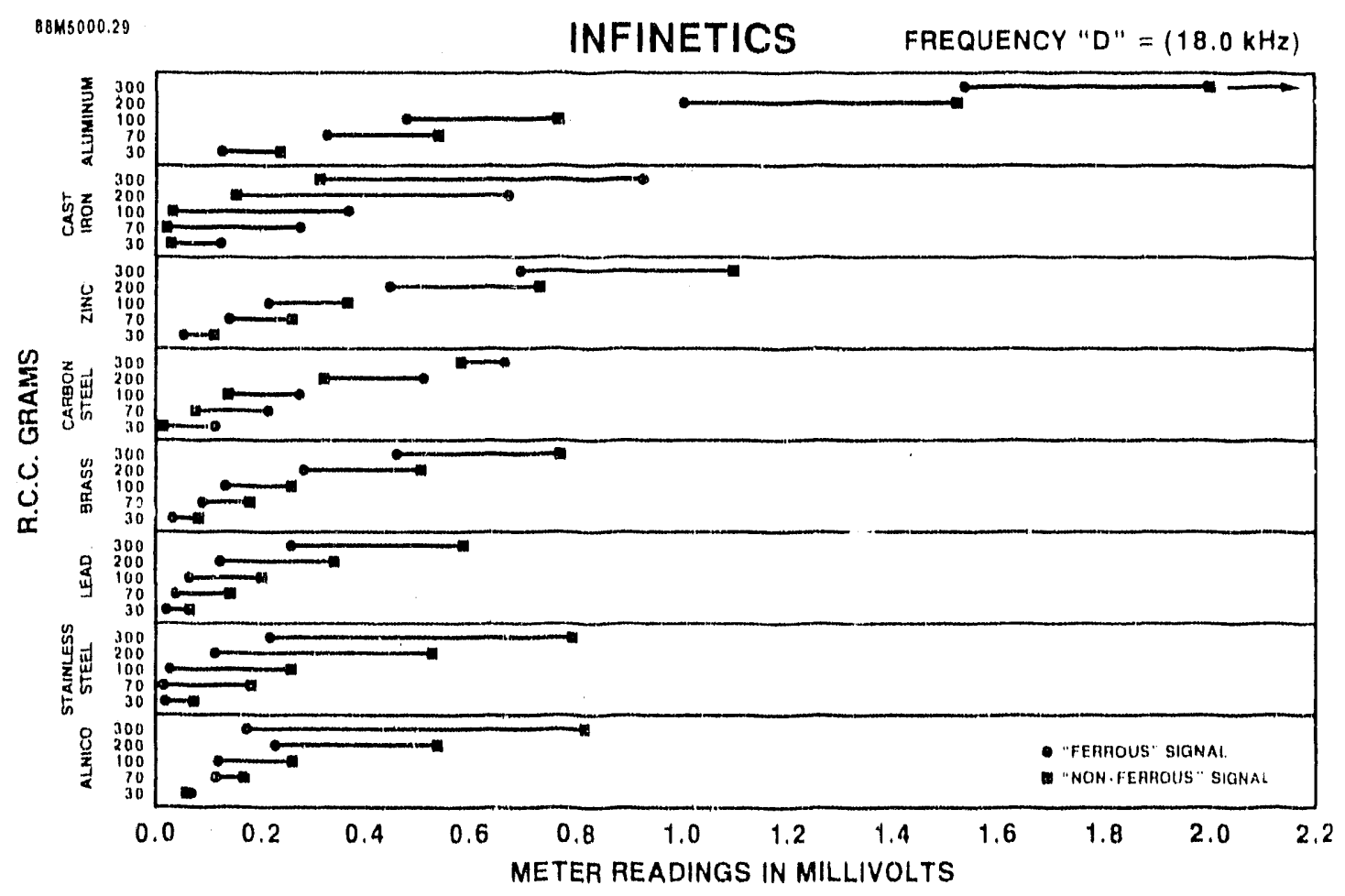

Figure 1-4 


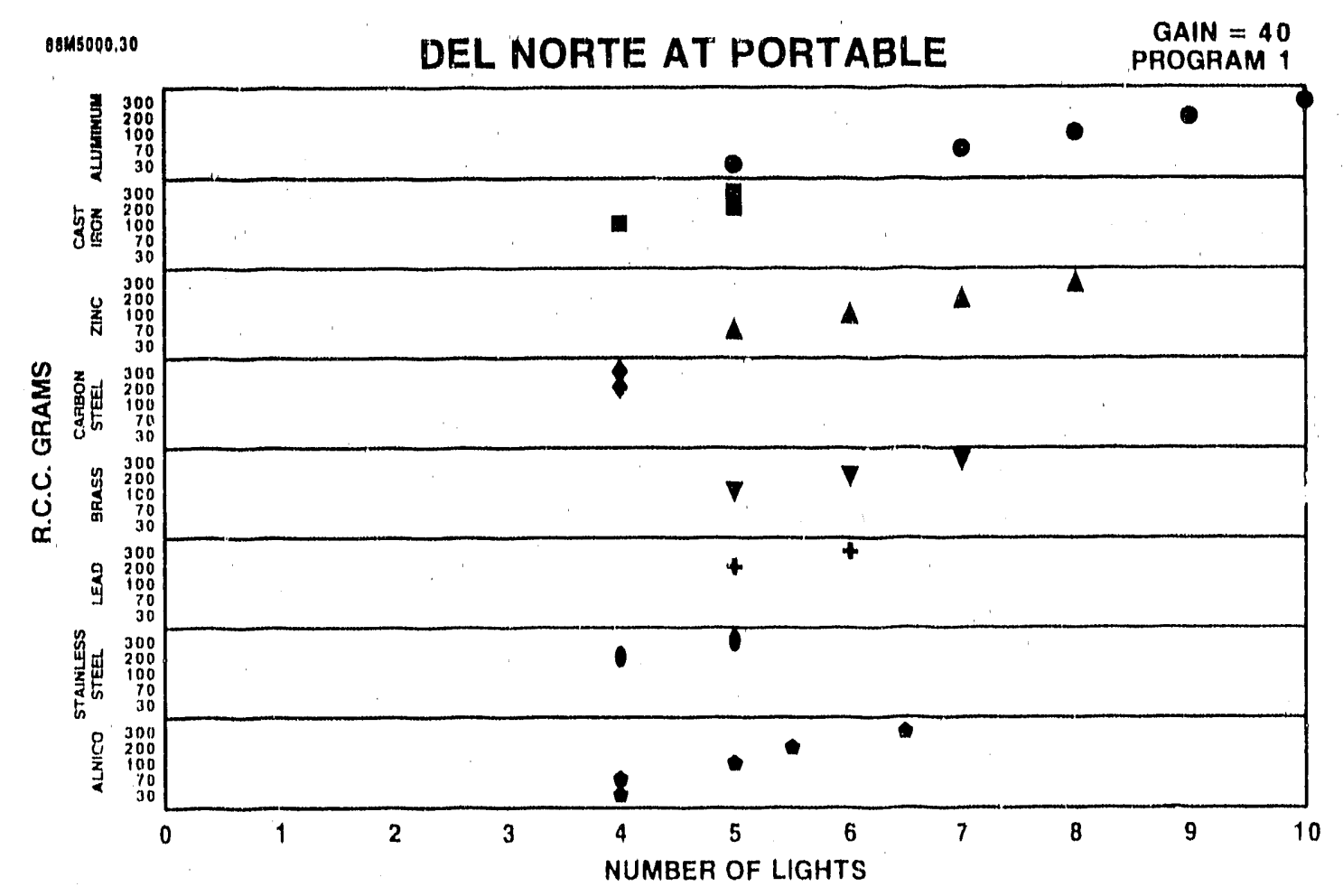

Figure 1-5

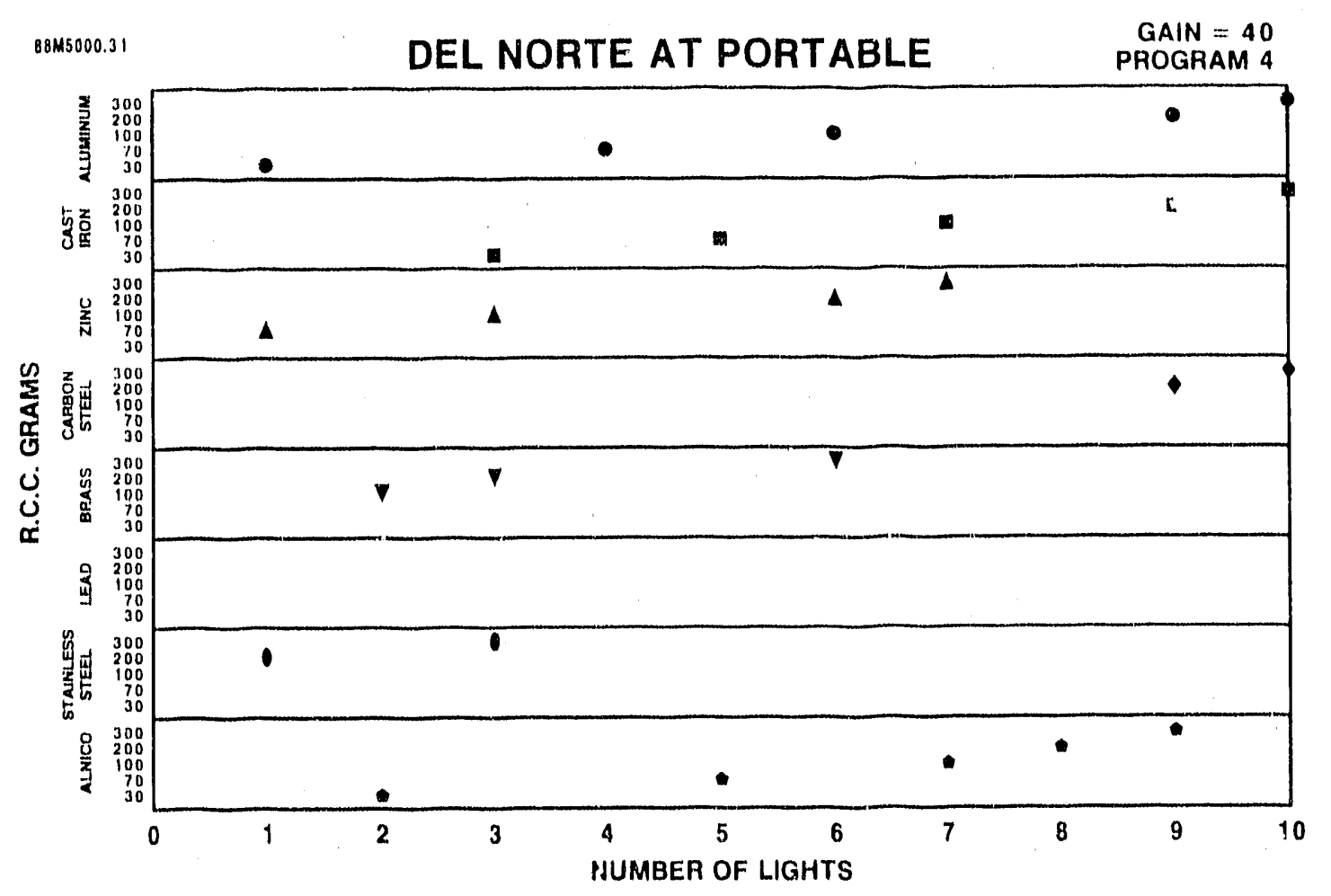

Figure 1-6 


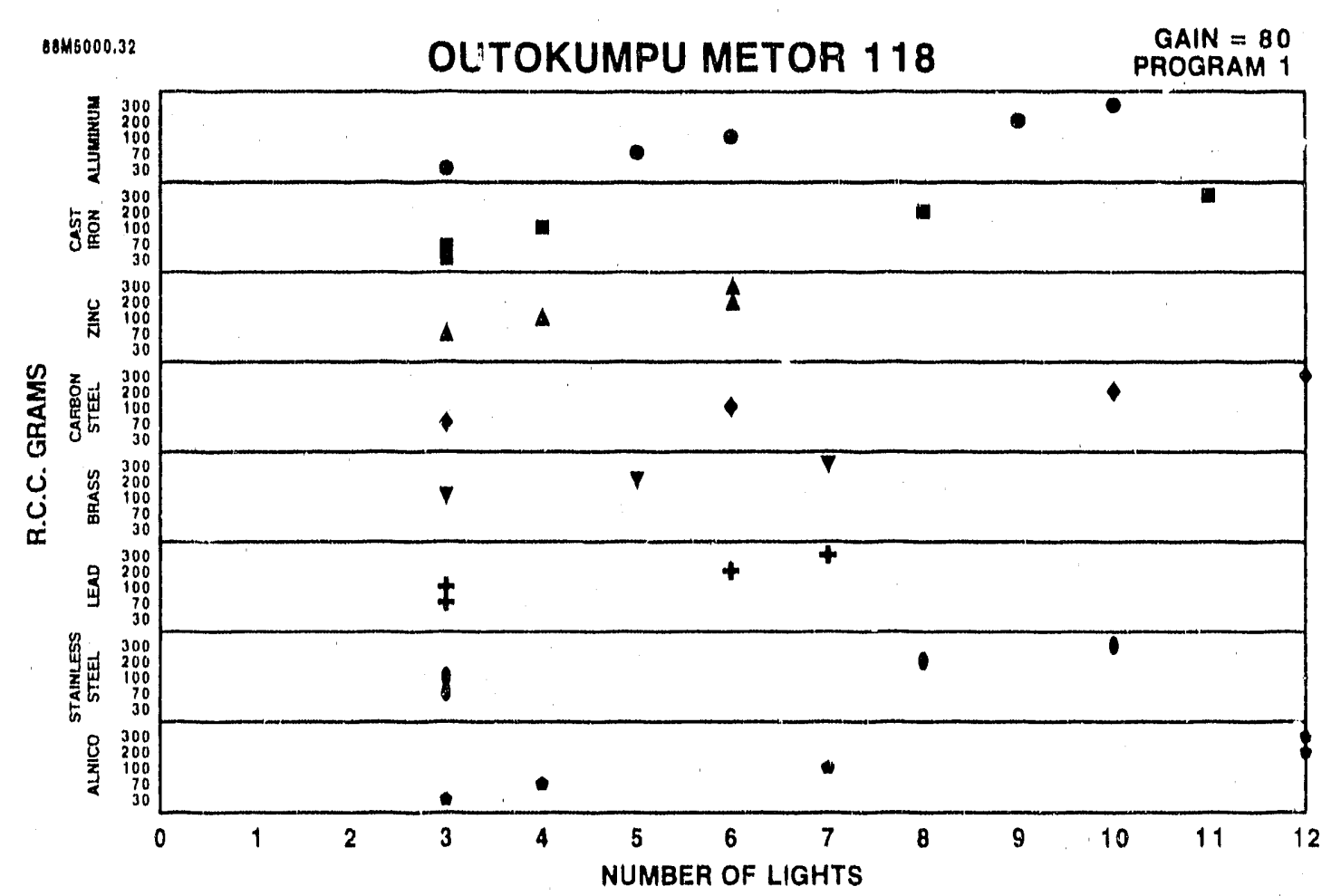

Figure 1-7

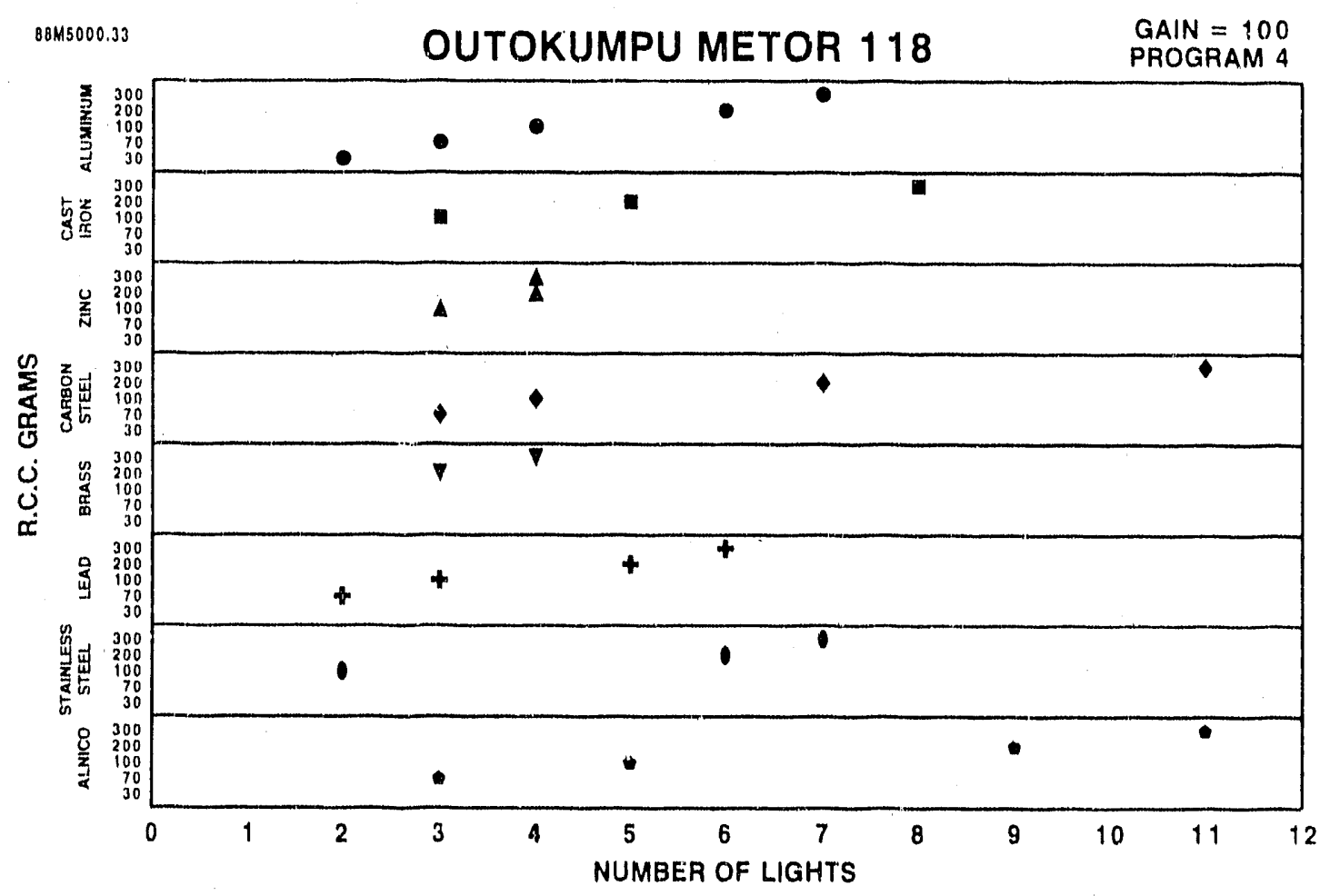

Figure 1-8 
INFINETICS R.C.C. TESTS

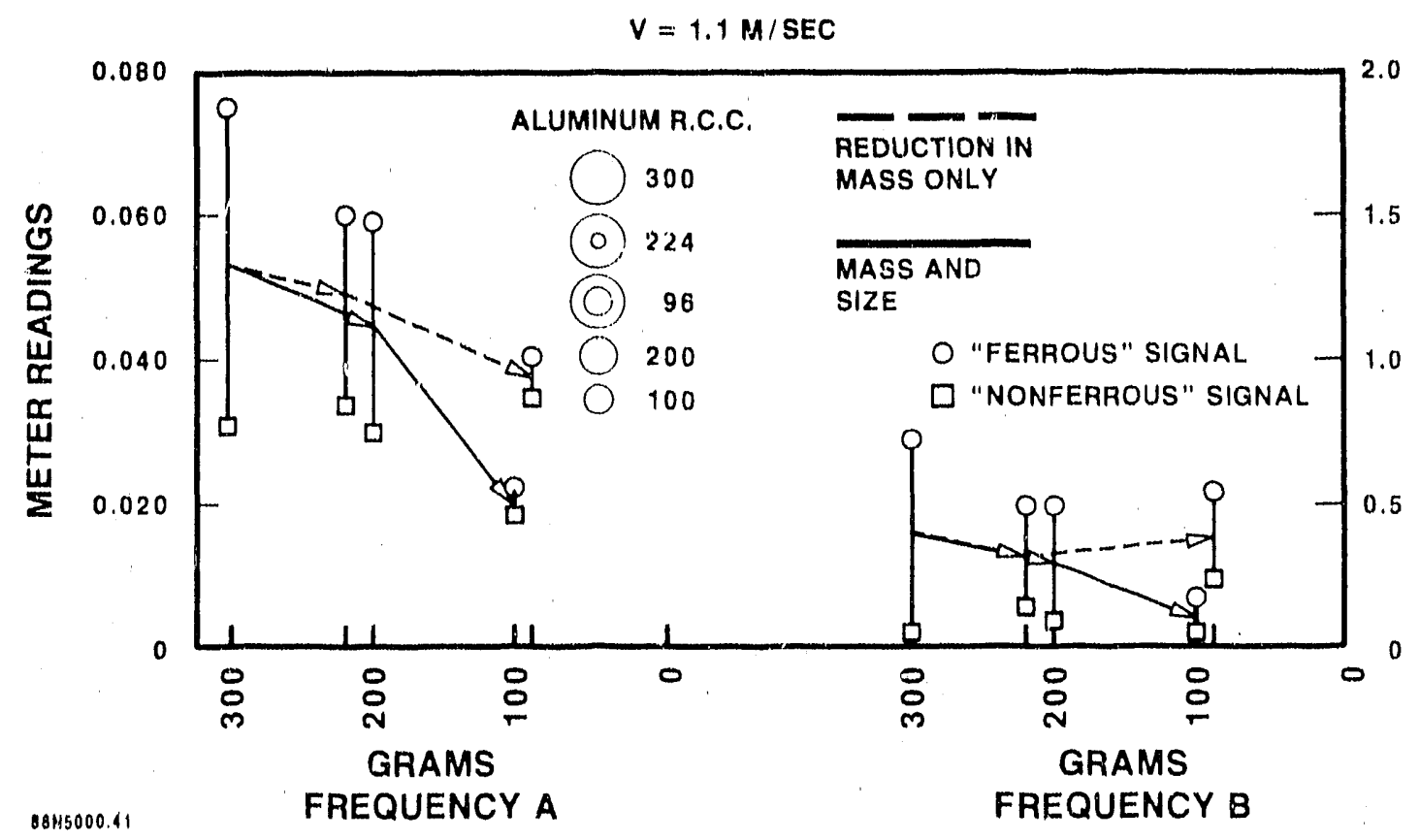

Figure 2-1

INFINETICS R.C.C. TESTS

$88 N 5000.43$

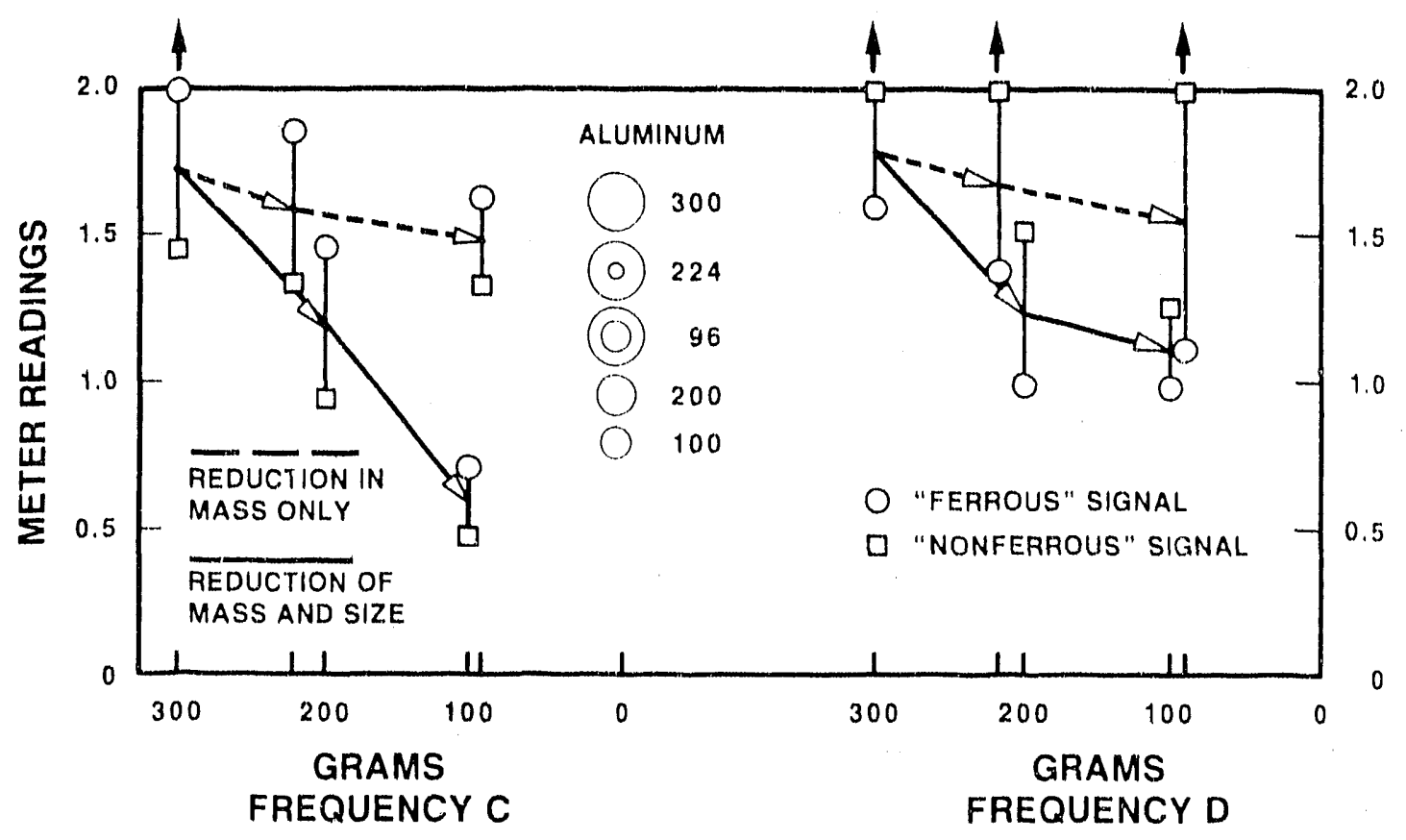

Figure 2-2 


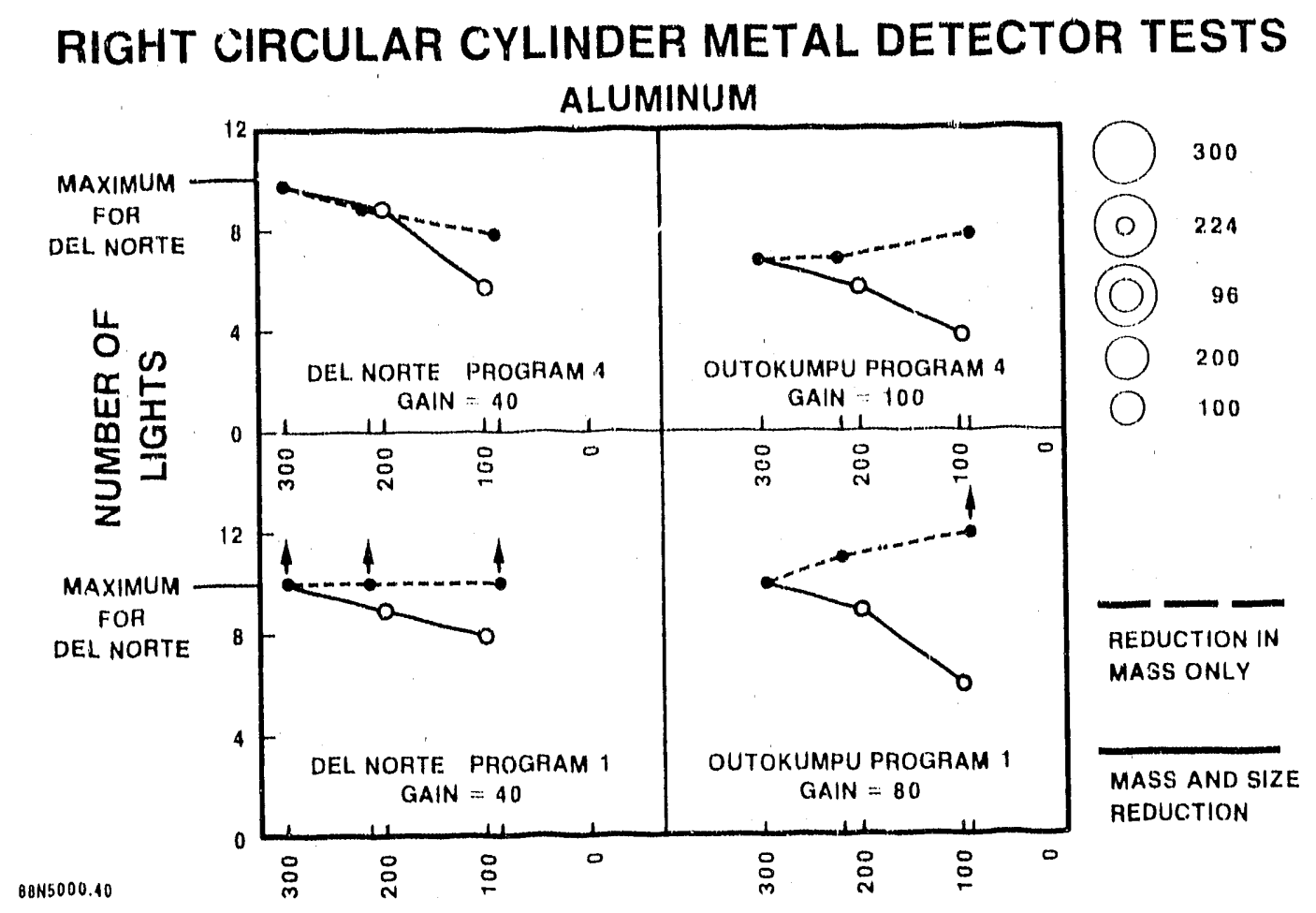

Figure $2-3$
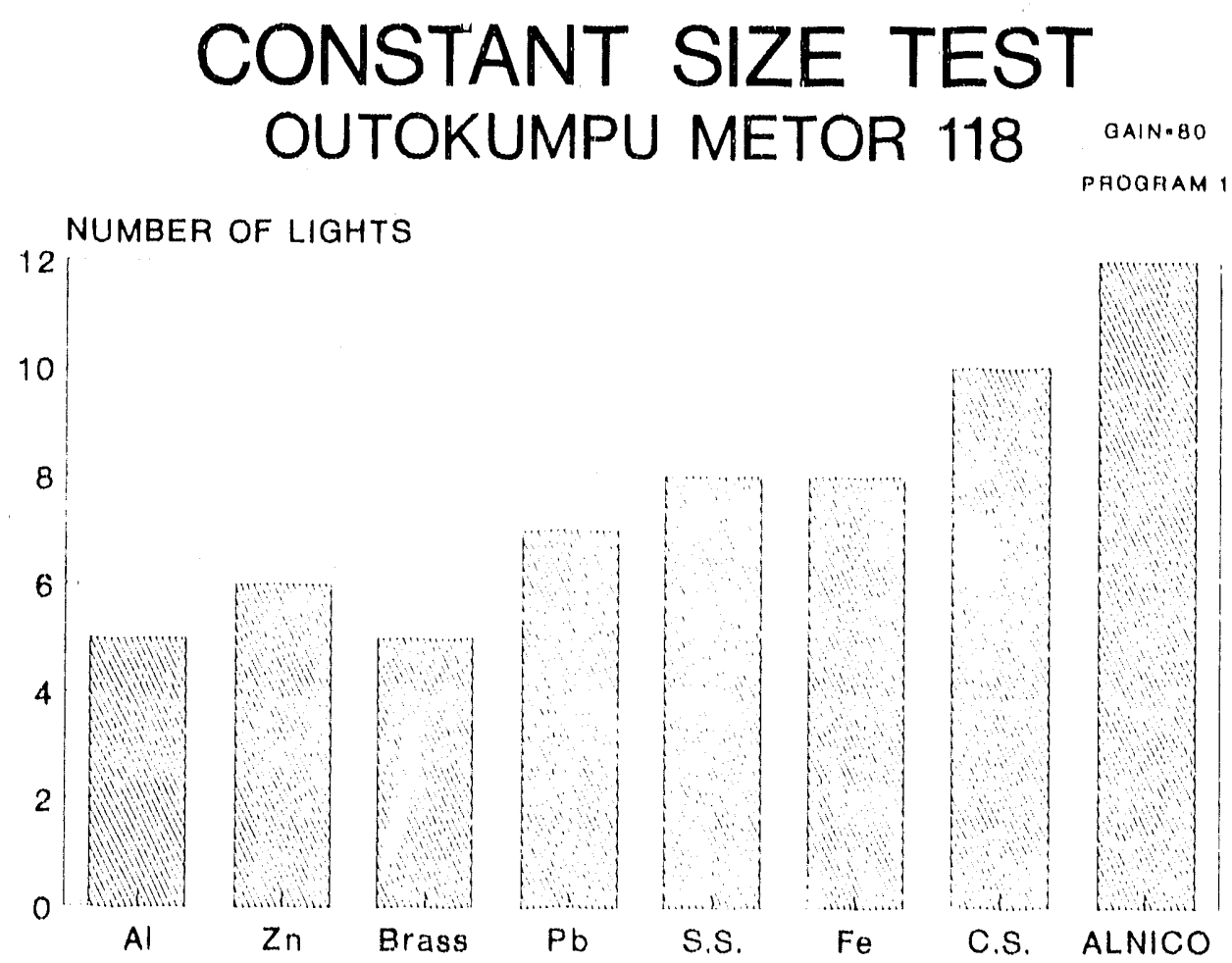

S.S.(Stalnless Steel) C.S.(Carbon steel)

Figure $3-1$ 


\section{CONSTANT SIZE TEST OUTOKUMPU METOR 118 axis -100}
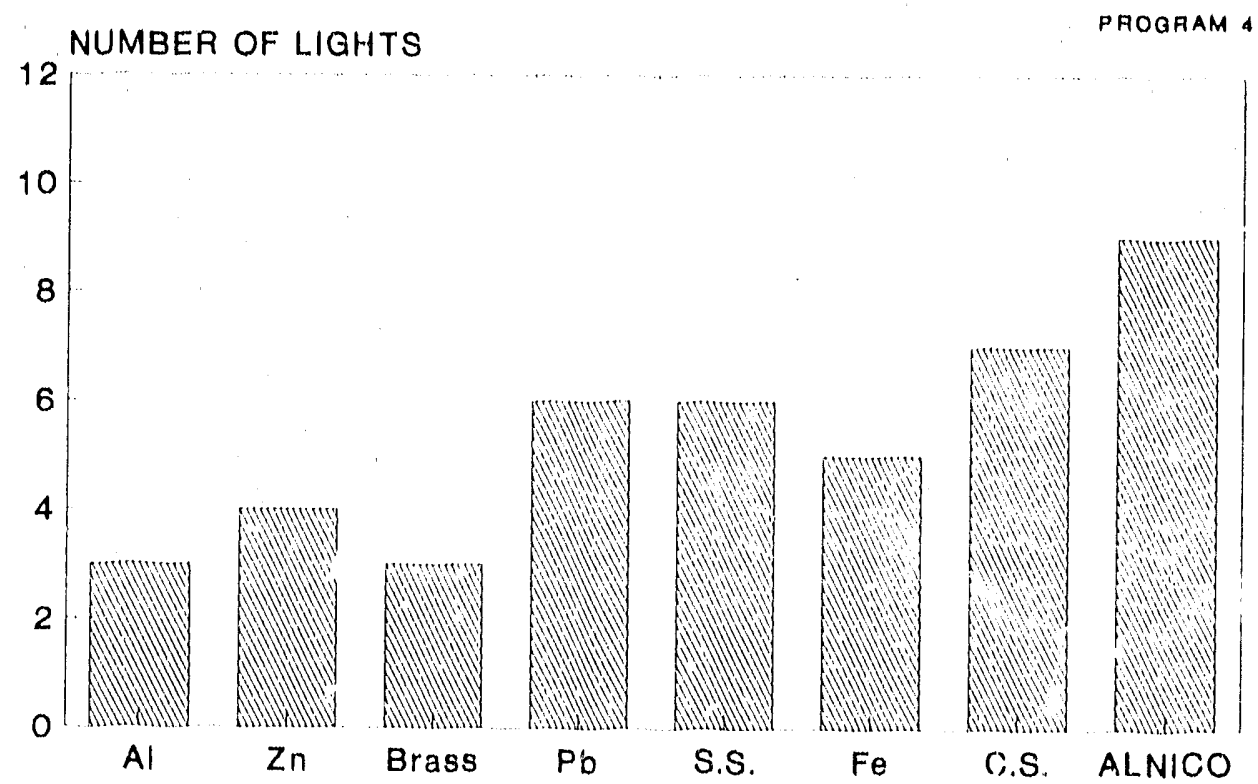

S.S.(Stalnless Steol) C.S.(Carbon Steel)

Figure $3-2$

\section{CONSTANT SIZE TEST DEL NORTE SENTRIE AT antulat} PROQRAM 1
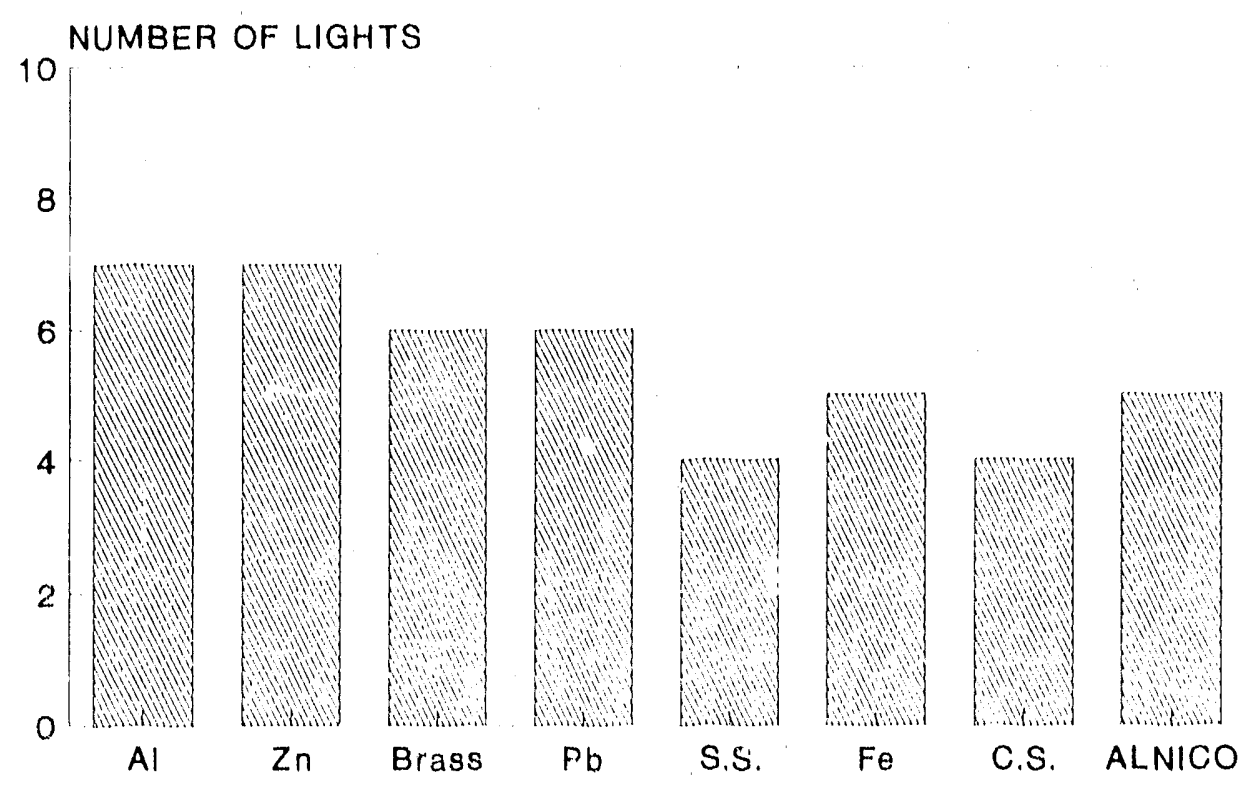

S.S.(Stalnless Steel) C.S.(Carbon Steel)

Figure $3-3$ 


\section{CONSTANT SIZE TEST

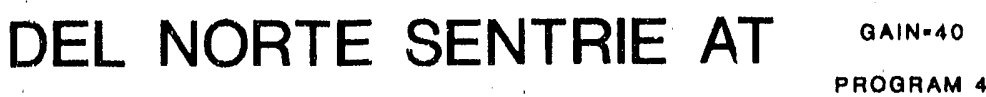

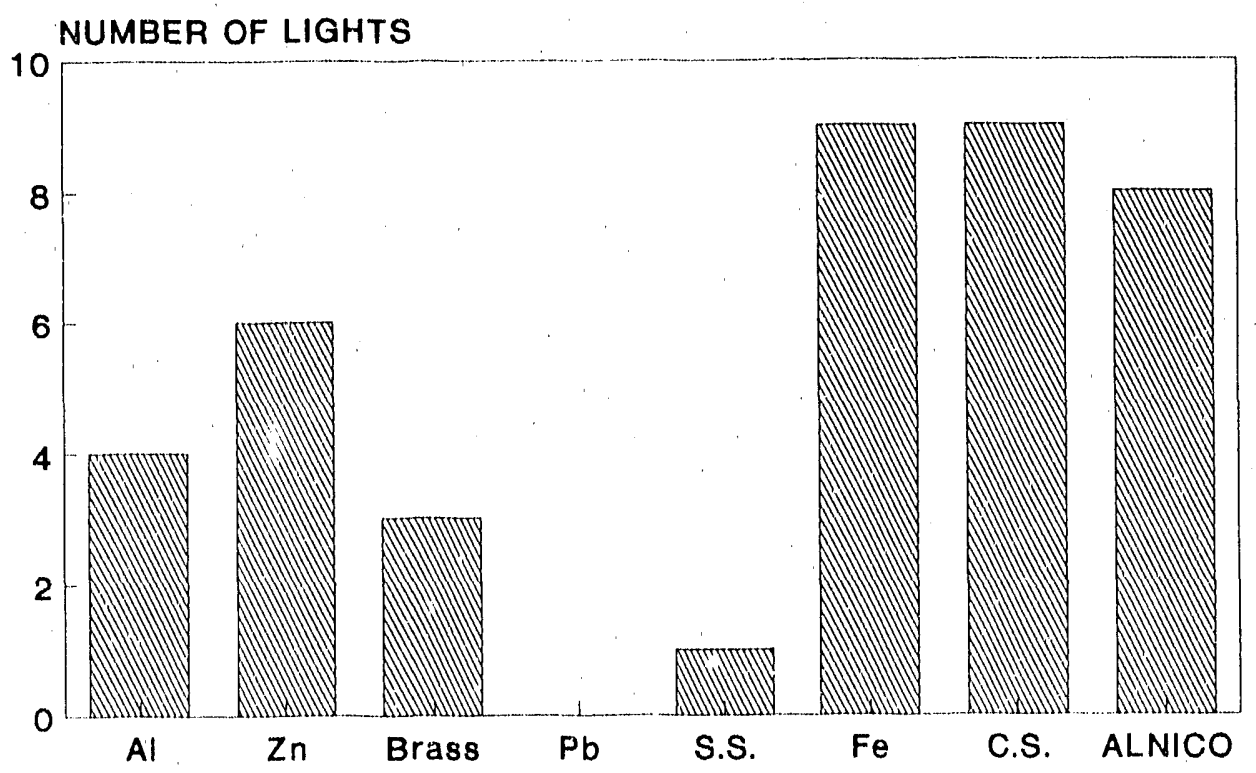

S.S.(Stalnless Steel) C.S.(Carbon Steel)

Figure $\quad 3-4$

\section{CONSTANT SIZE TEST INFINETICS}

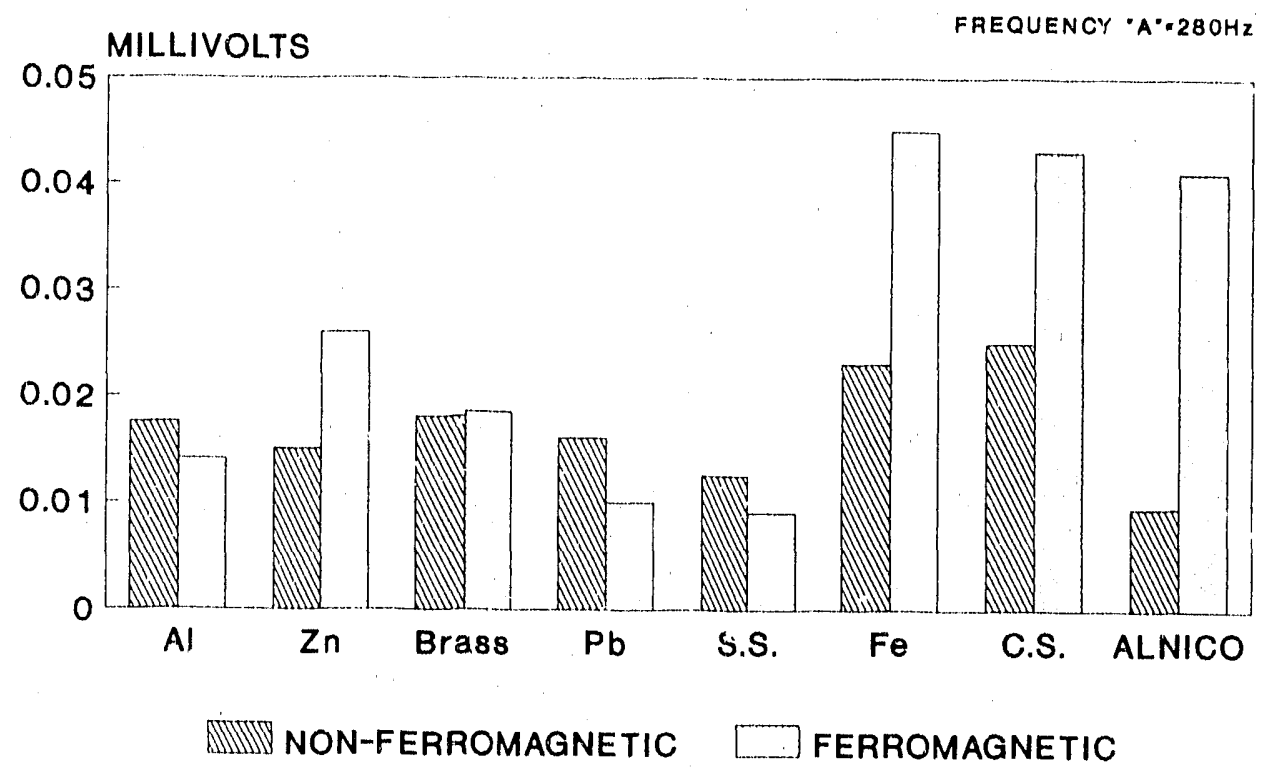

S.S.(Stalnless Steol) C.S.(Carbon Steel)

Figure 3-5 


\section{CONSTANT SIZE TEST INFINETICS}

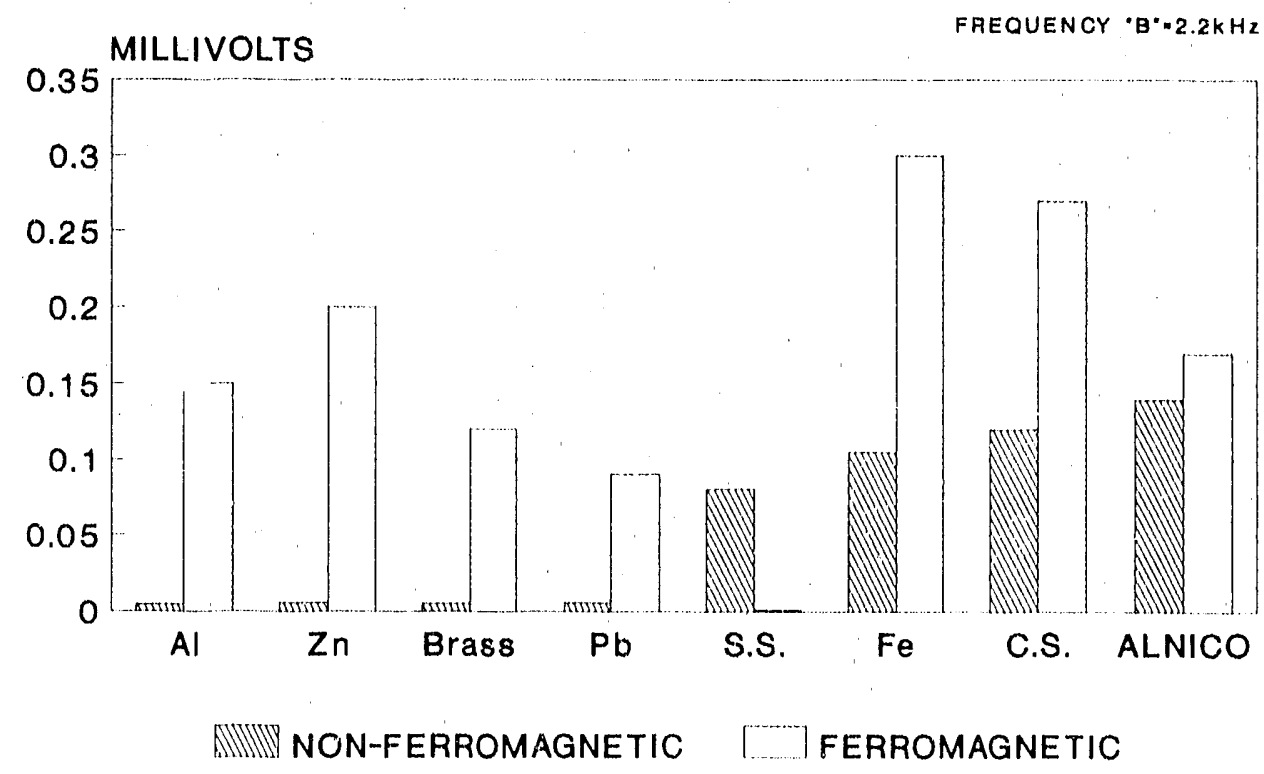

S.S.(Stainless Steel) C.S.(Carbon Steel)

Figure $3-6$

\section{CONSTANT SIZE TEST INFINETICS}

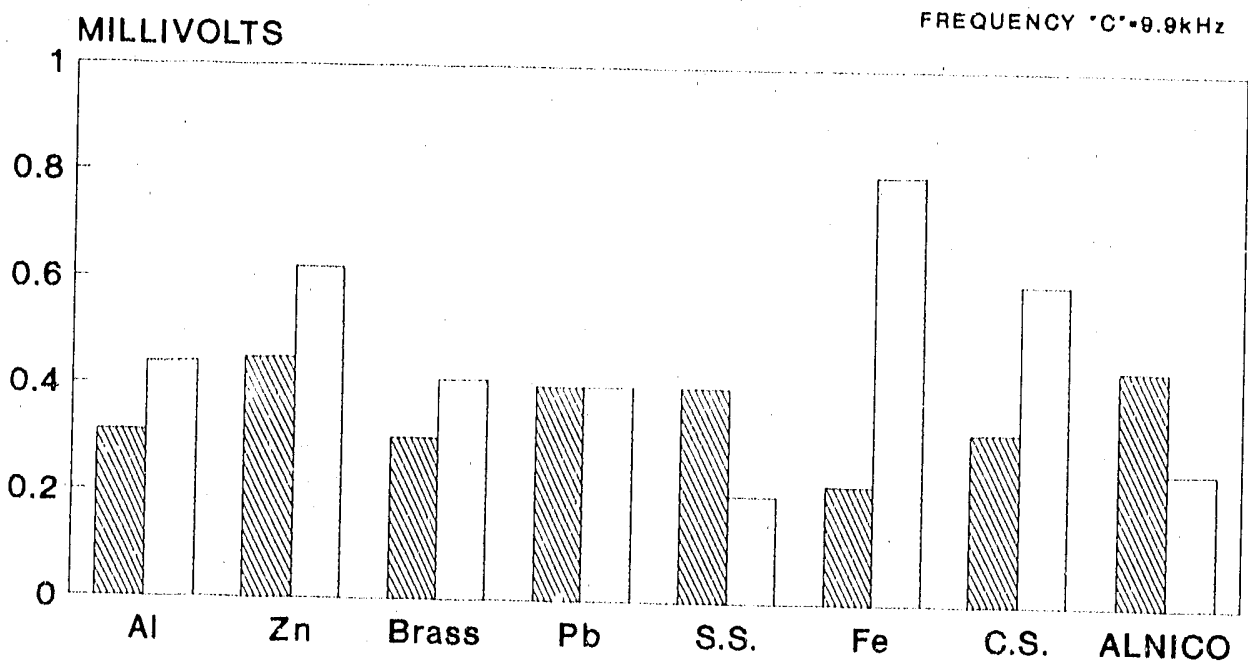

AIIIV NON-FERROMAGNETIC [-!] JERROMAGNETIC

S.S.(Stainless Steel) C.S.(Carbon Steel) 


\section{CONSTANT SIZE TEST INFINETICS}

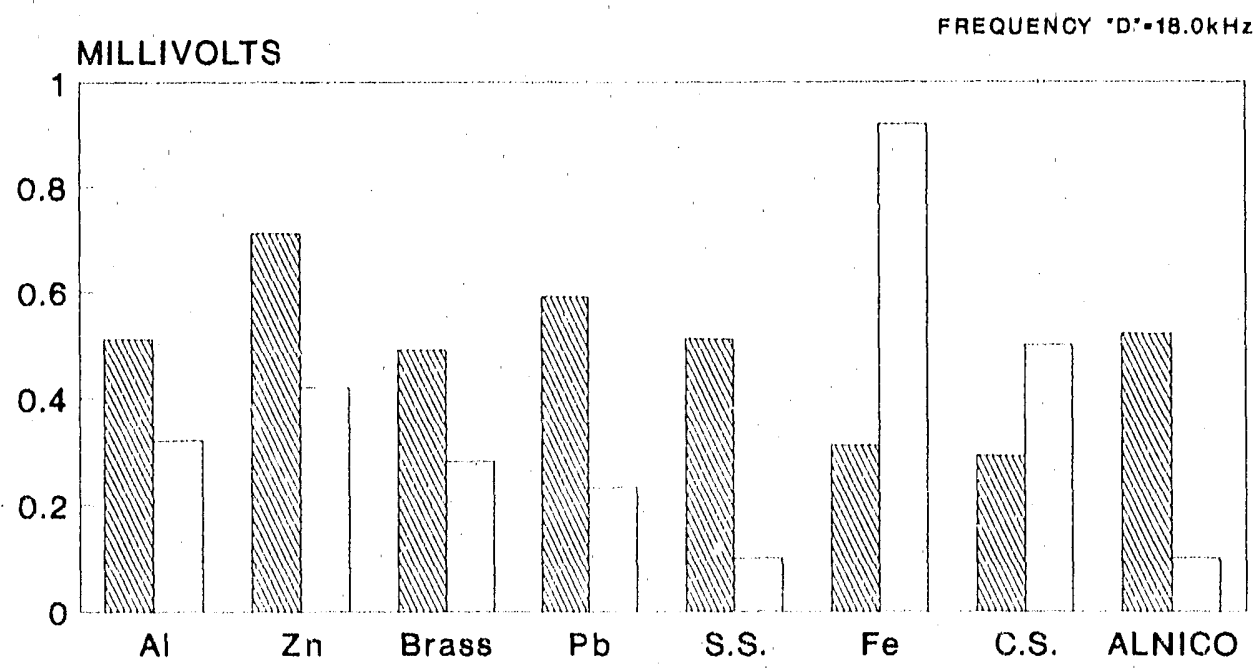

AIIIVY NON-FERROMAGNETIC […] FERROMAGNETIC

S.S.(Stainless Steel) C.S.(Carbon Steel)

Fiqure 3-8

DEL NORTE PORTABLE AT VELOCITY TEST

PROGRAM $4 \quad$ GAIN $=35$

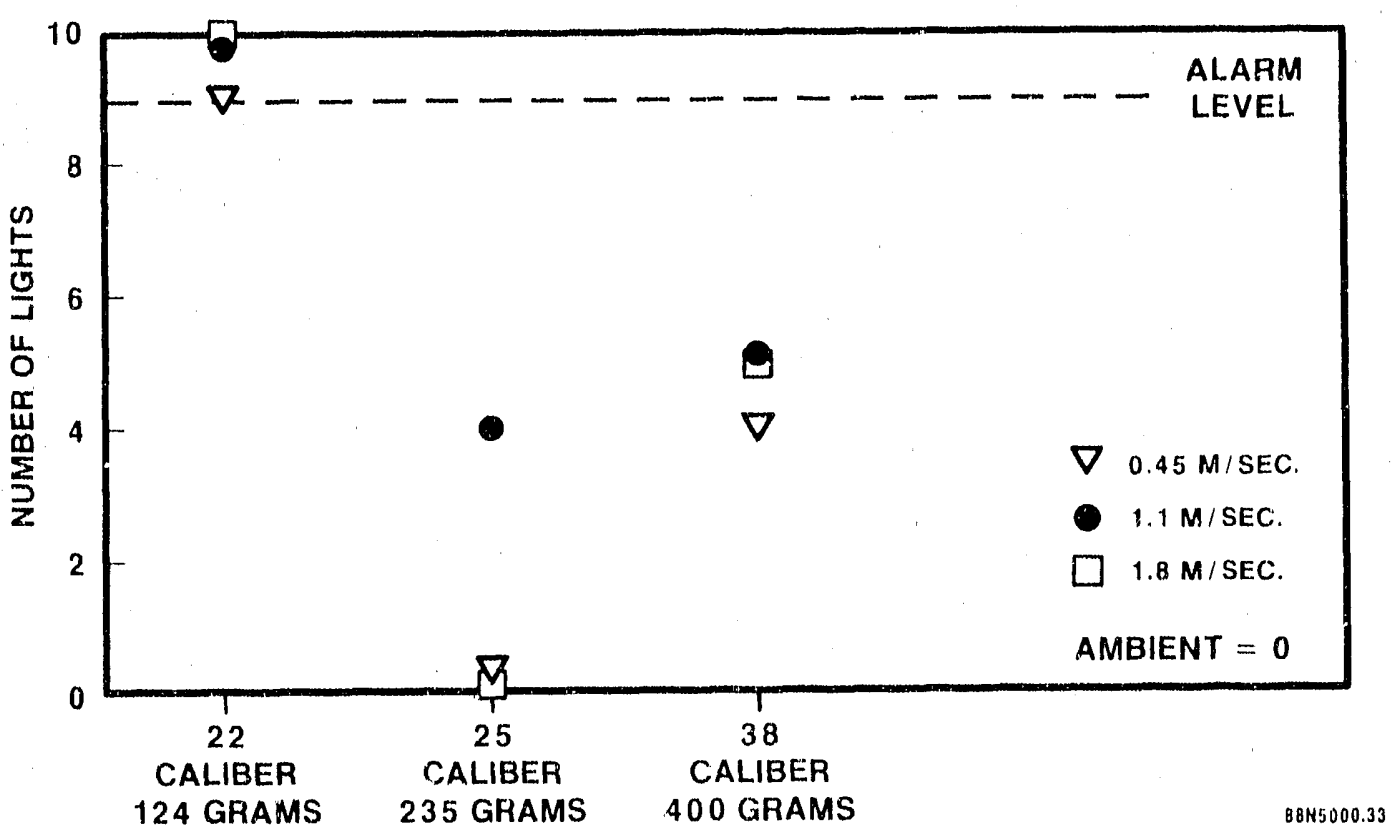

Figure 4-1 


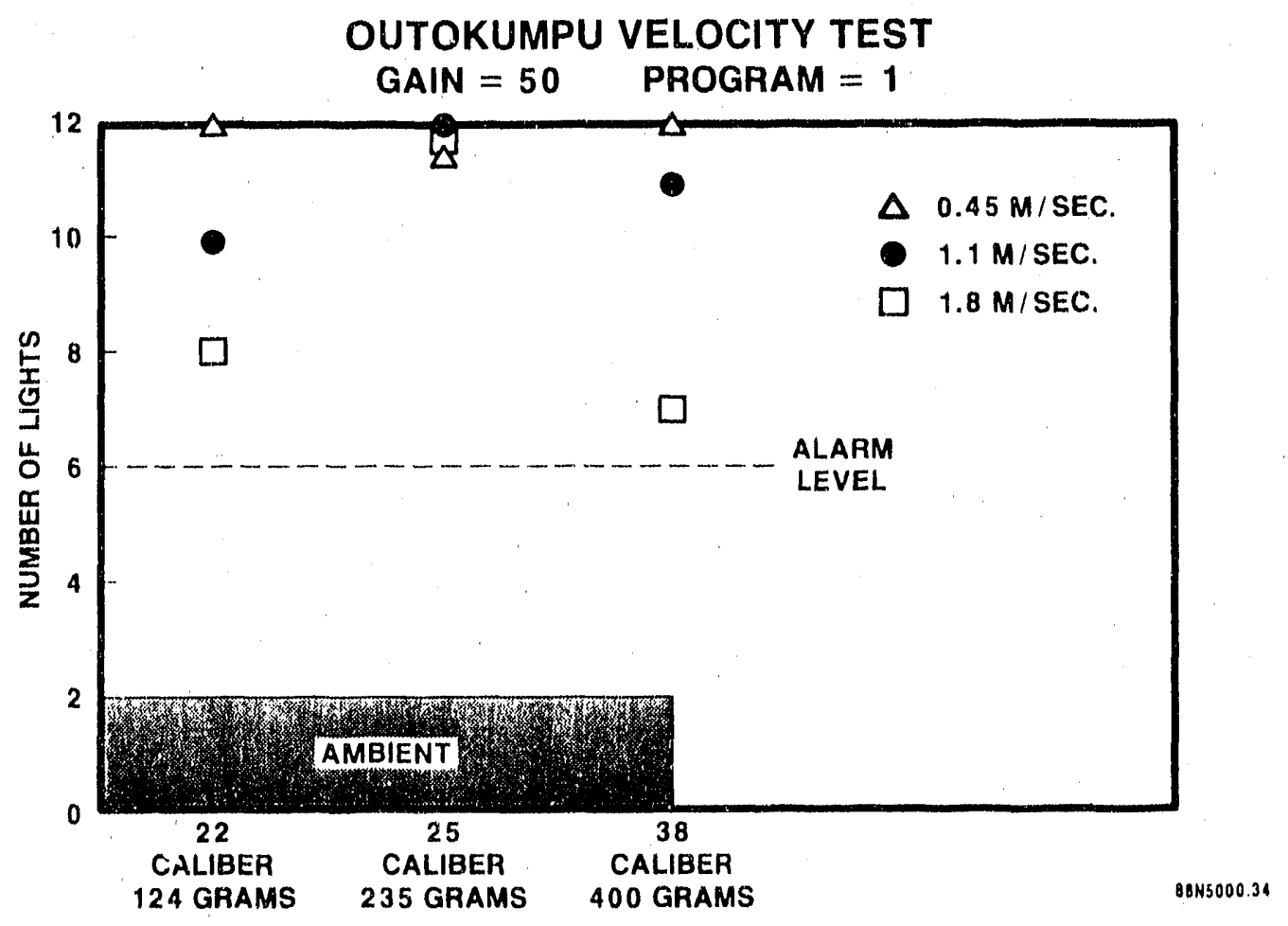

Figure $4-2$

\section{Del Norte Sentrie AT Program 1}

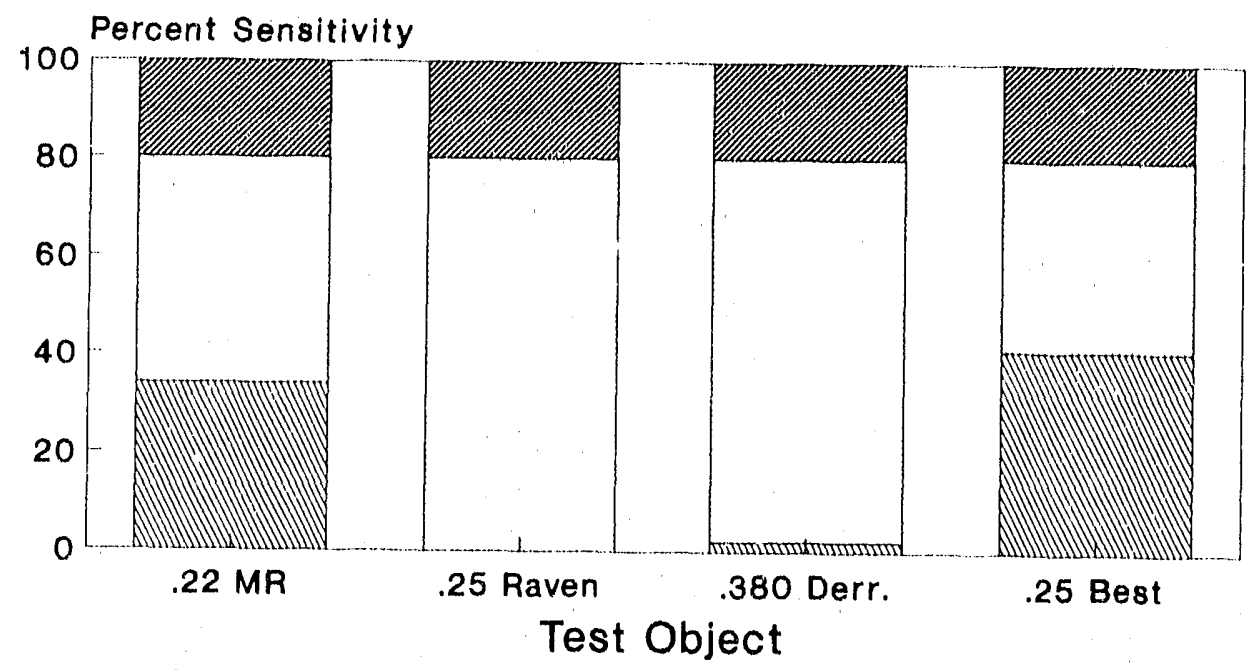

AMIIV NO DETECTION [DIDTECTION BUIM HIGH FALSE ALARM

Figure 5-1 


\section{Del Norte Sentrie AT Program 3}
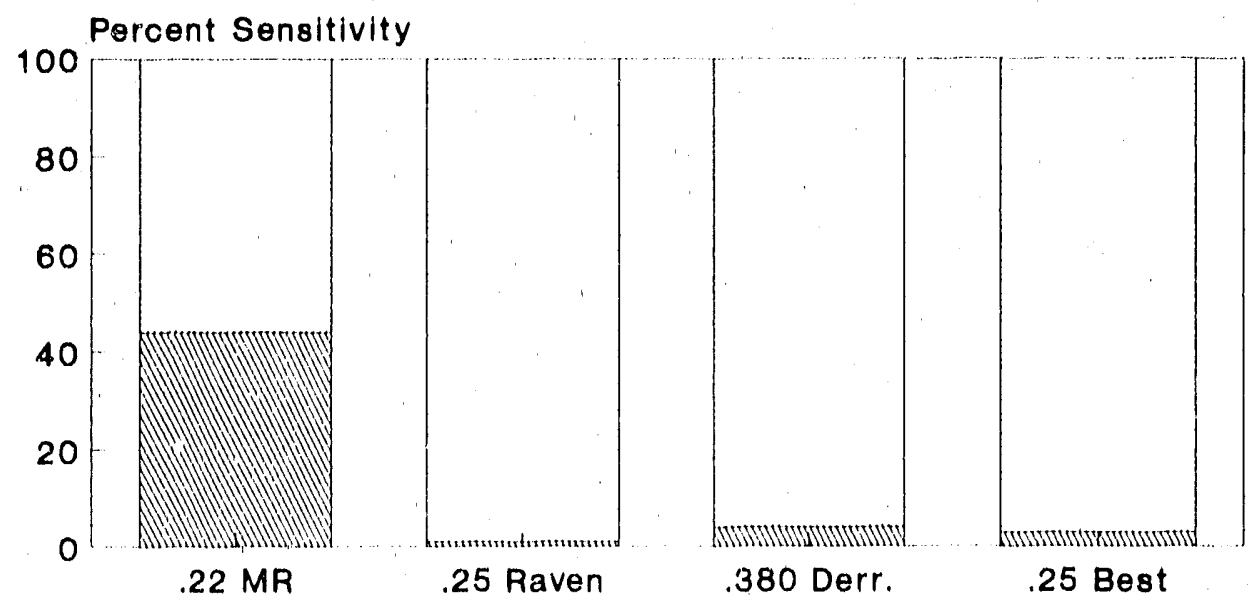

Test Object

MHIN NO DETECTION I'.'IDETECTION

Figure 5-2

Del Norte Sentrie AT

Program 4
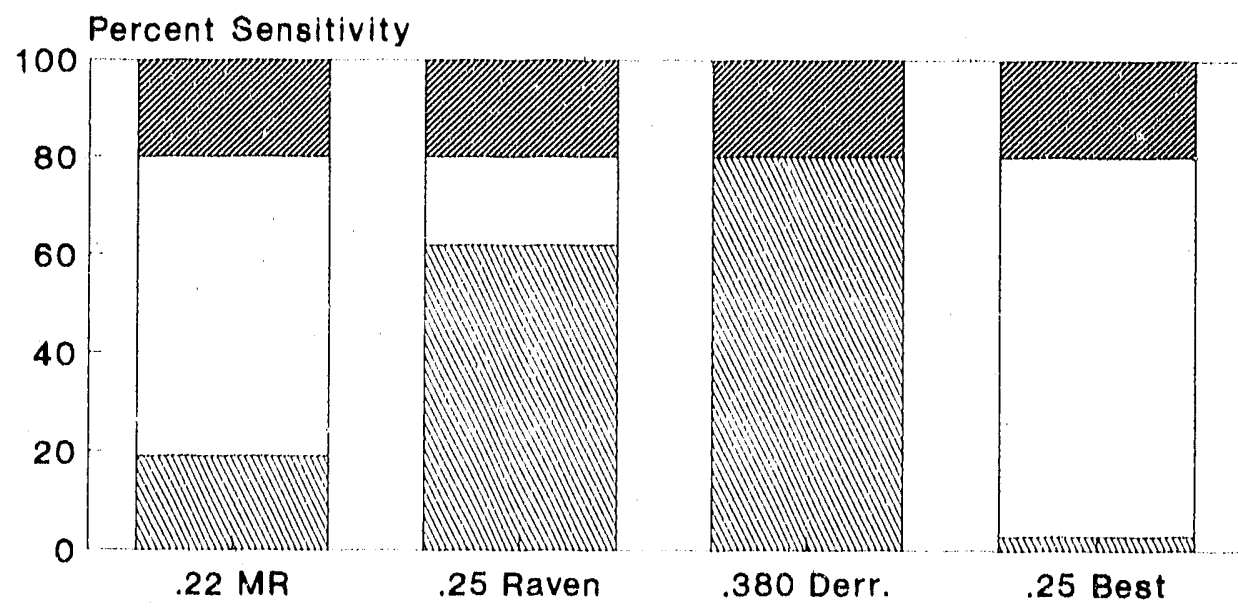

Test Object

AIIITINO DETECTION W...IDETECTION YIIIA HIGH FALSE ALARM

Figure 5-3 


\section{Del Norte Sentrie AT Program 5}
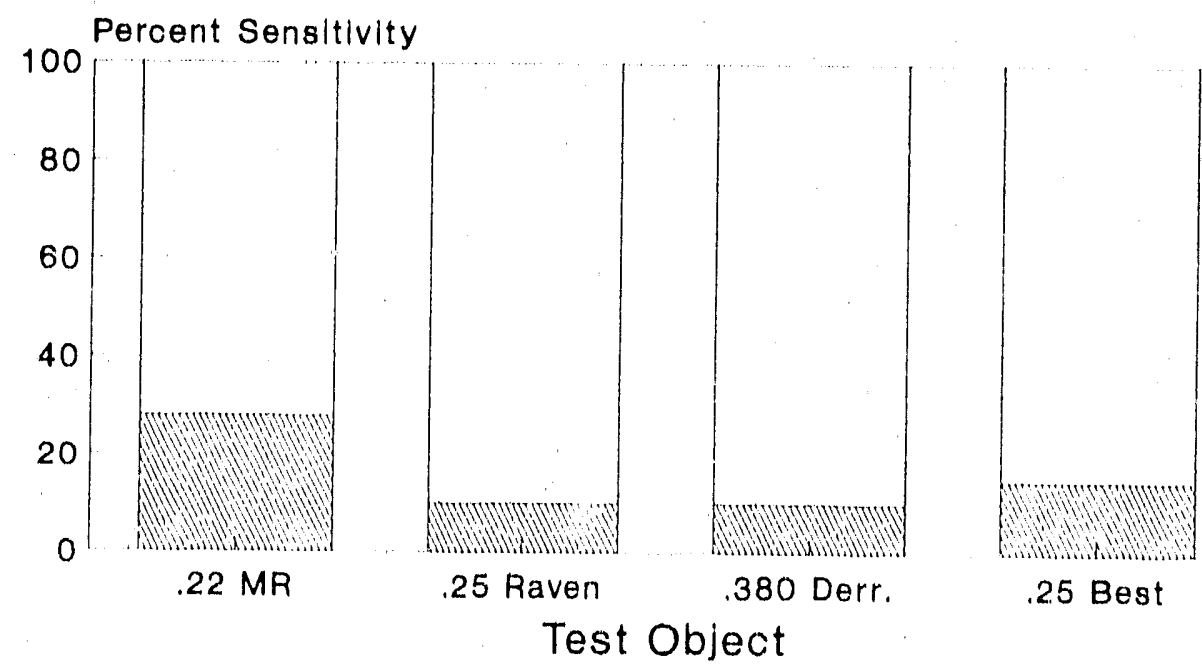

.25 Best

RWW NO DETECTION I IDETECTION

Figure $5-4$

Del Norte Sentrie HS Descrimination Mode

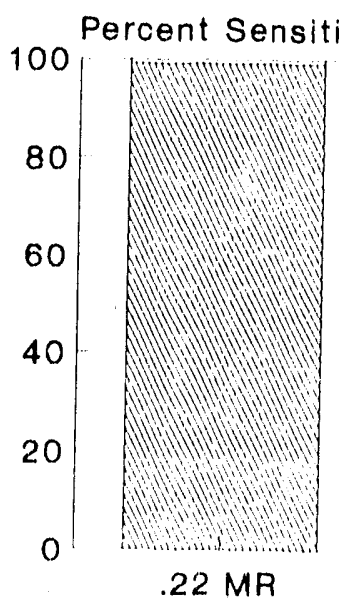

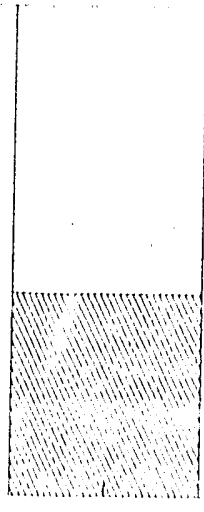

.25 Raven

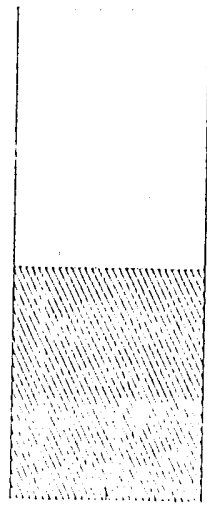

.380 Derr.

Test Object

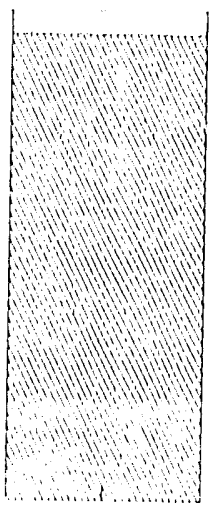

25 Best

RAIIII NO DETECTION I IETECTION

Figure $5-5$ 


\section{Del Norte Sentrie HS}

High Sensitivity Mode
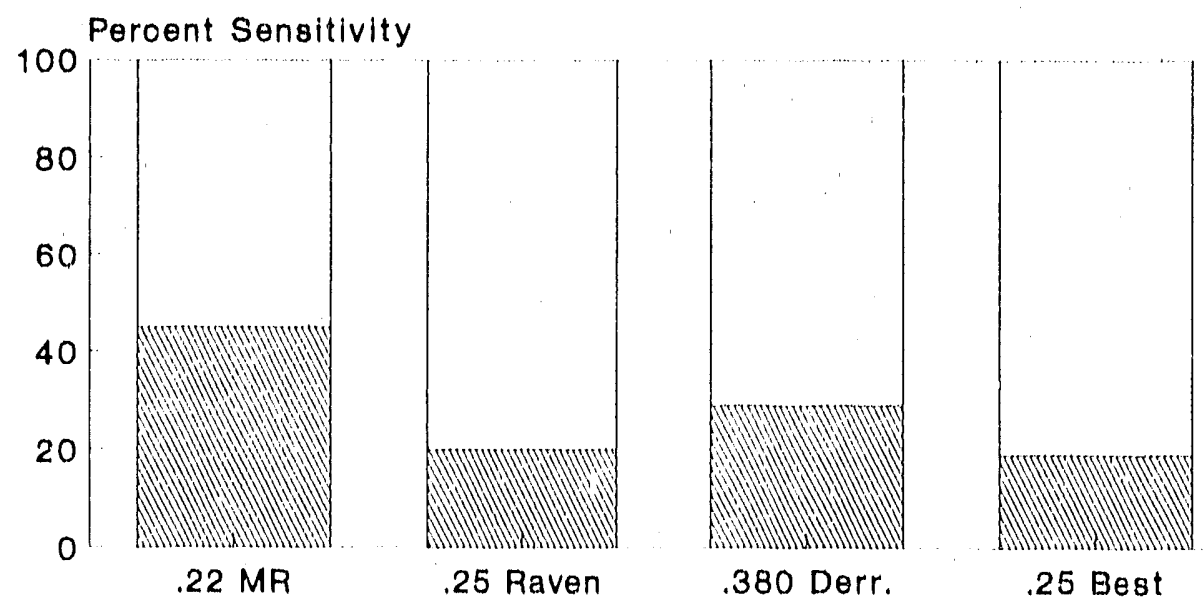

Test Object

AMIN NO DETECTION I. IDETECTION

Figure $5-6$

\section{Outokumpu Metor 118 Program 3 (Normal Sensitivity)}
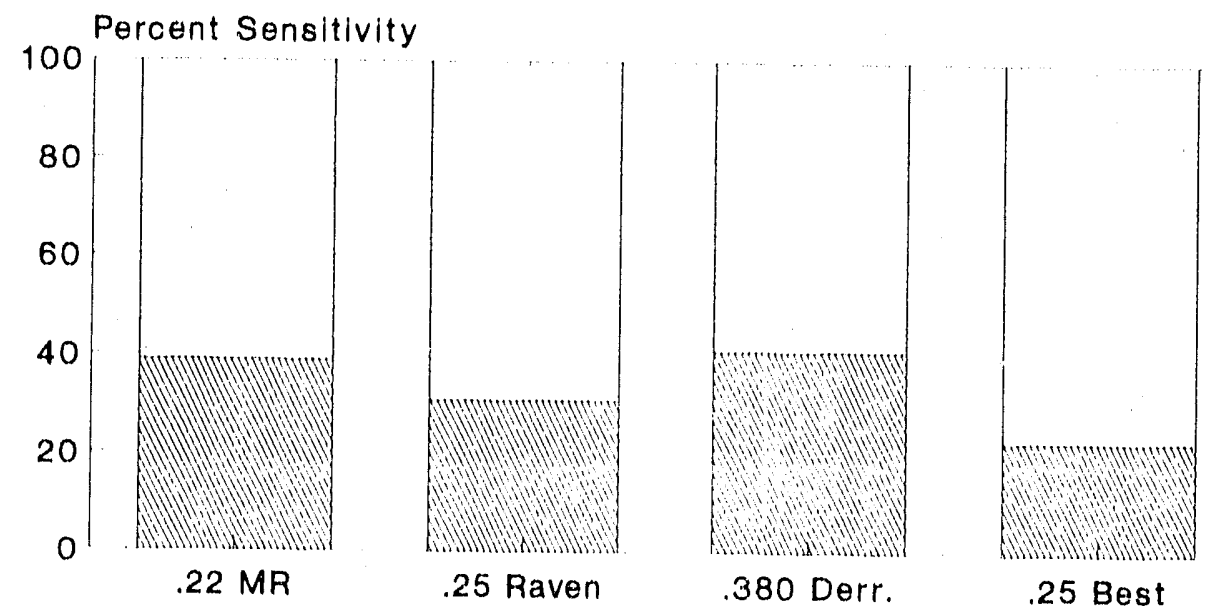

Test Object

AMIIY NO DETECTION IDETECTION

Figure 5-7 


\section{Outokumpu Metor 118 Program 8 (High Sensitivity)}
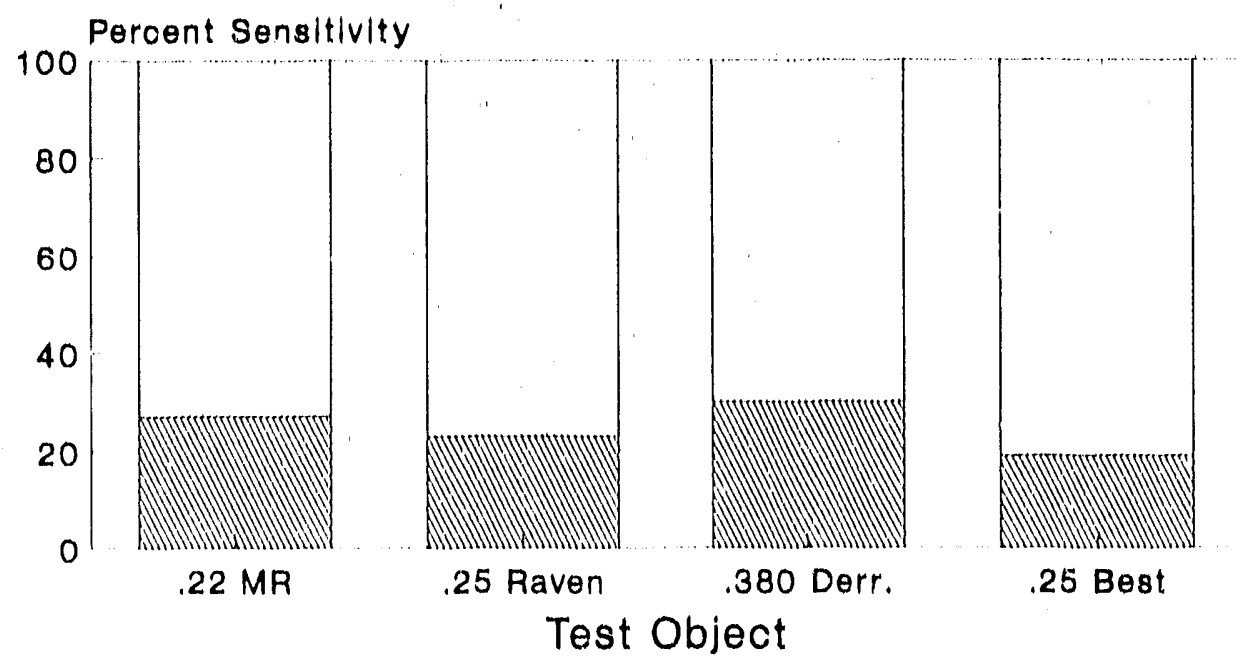

MAIIV NO DETECTION [....IDETECTION

Figure $5-8$

\section{Outokumpu Metor 120 Program 01 (Normal Sensitivity)}

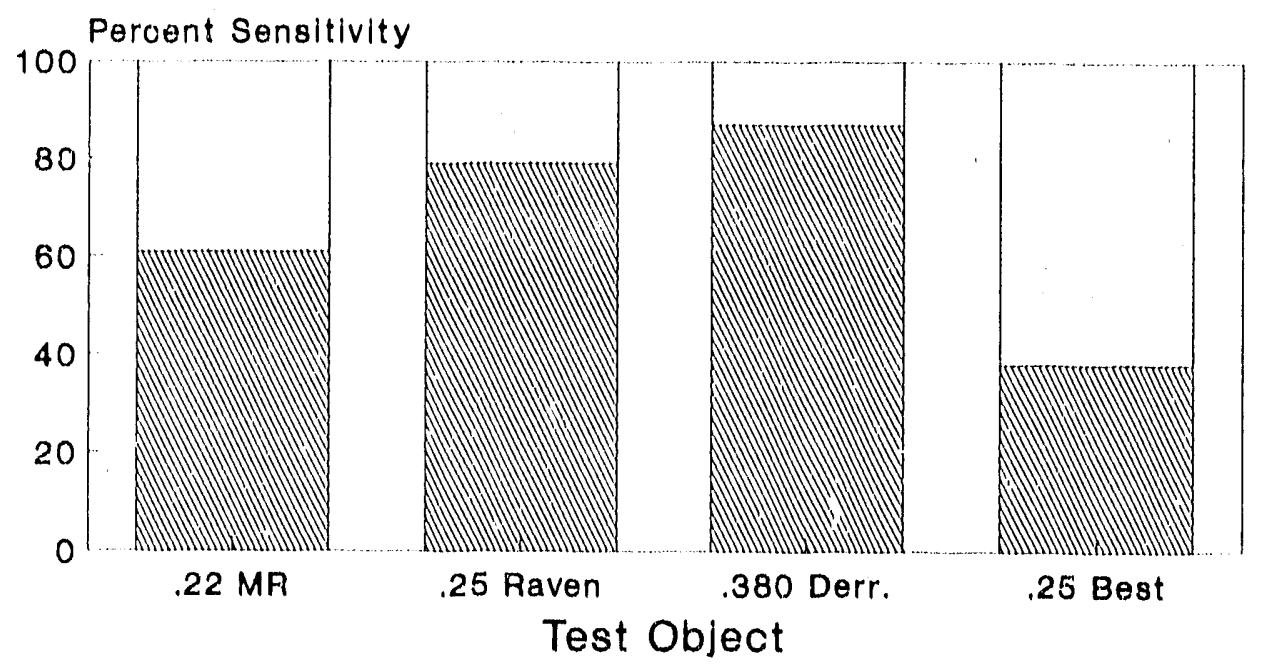

AMIIY NO DETECTION [-.]DETECTION

Figure 5-9 


\section{Outoliumpu Metor 120 Program 00 (High Sensitivity)}

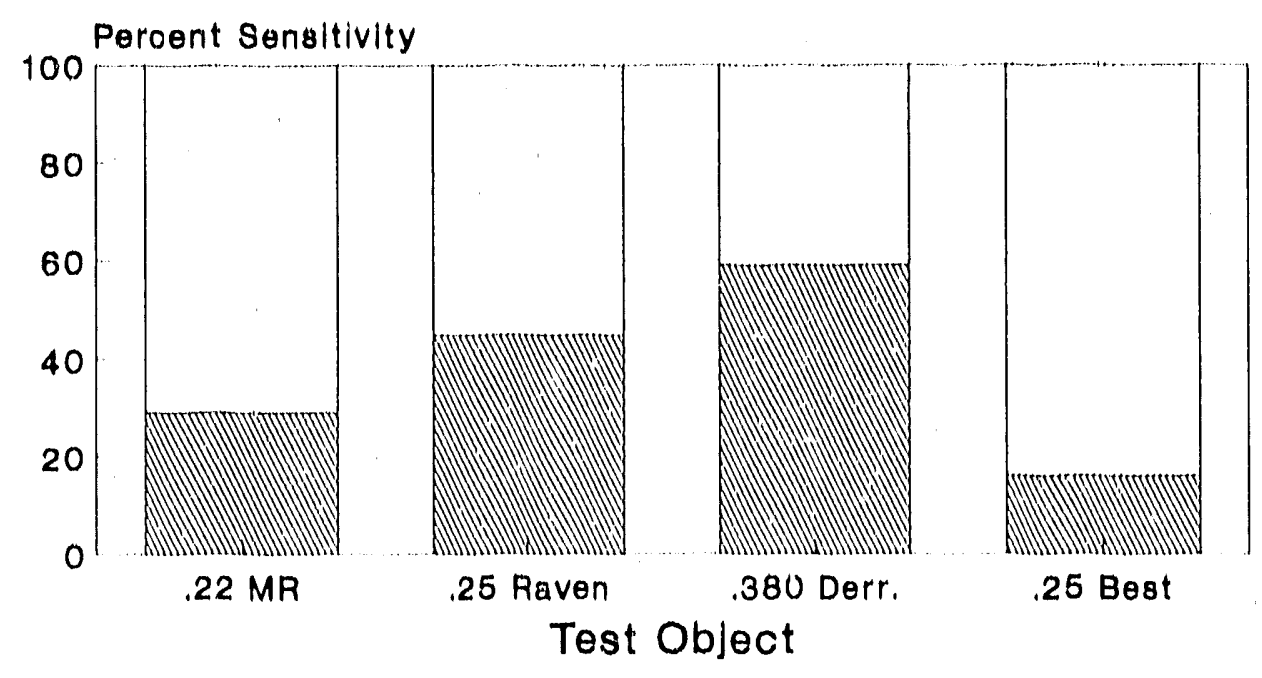

AMIVY NO DETECTION I...IDETECTION

Figure 5-10

\section{Infinetics FRISKEM 570 Continuous Wave}

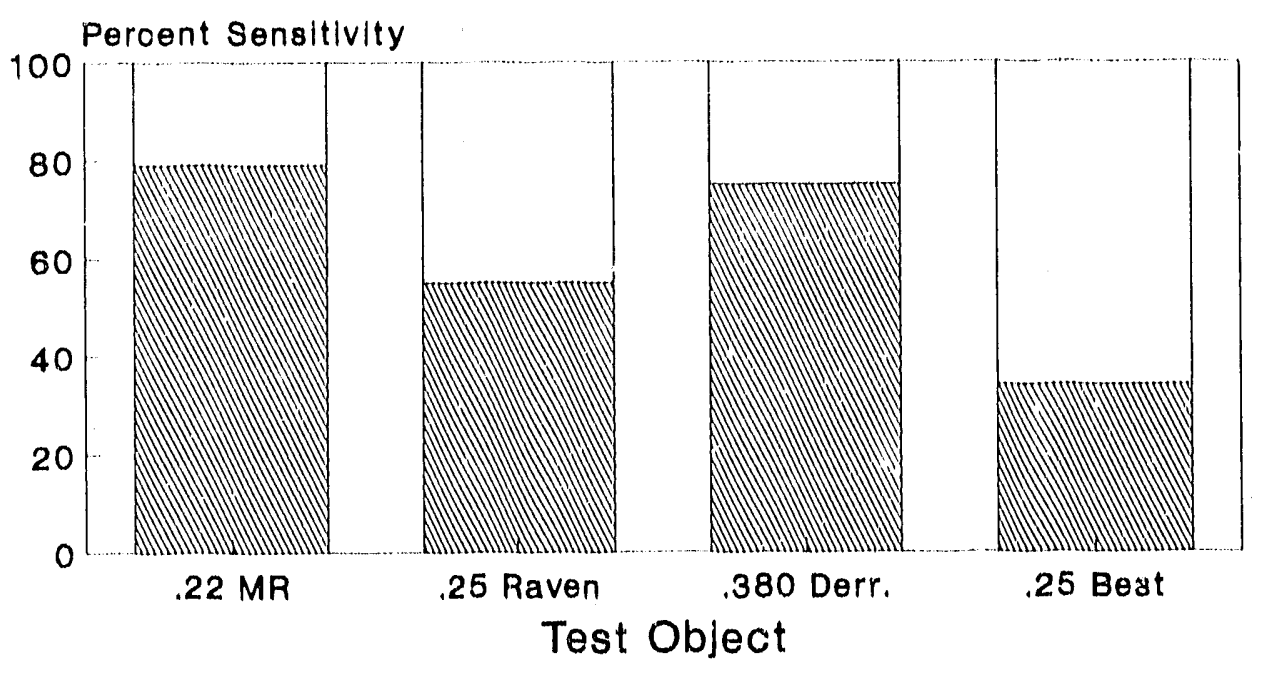

AMUYY NO DETECTION I. JDETECTION

Figure 5-1.1 


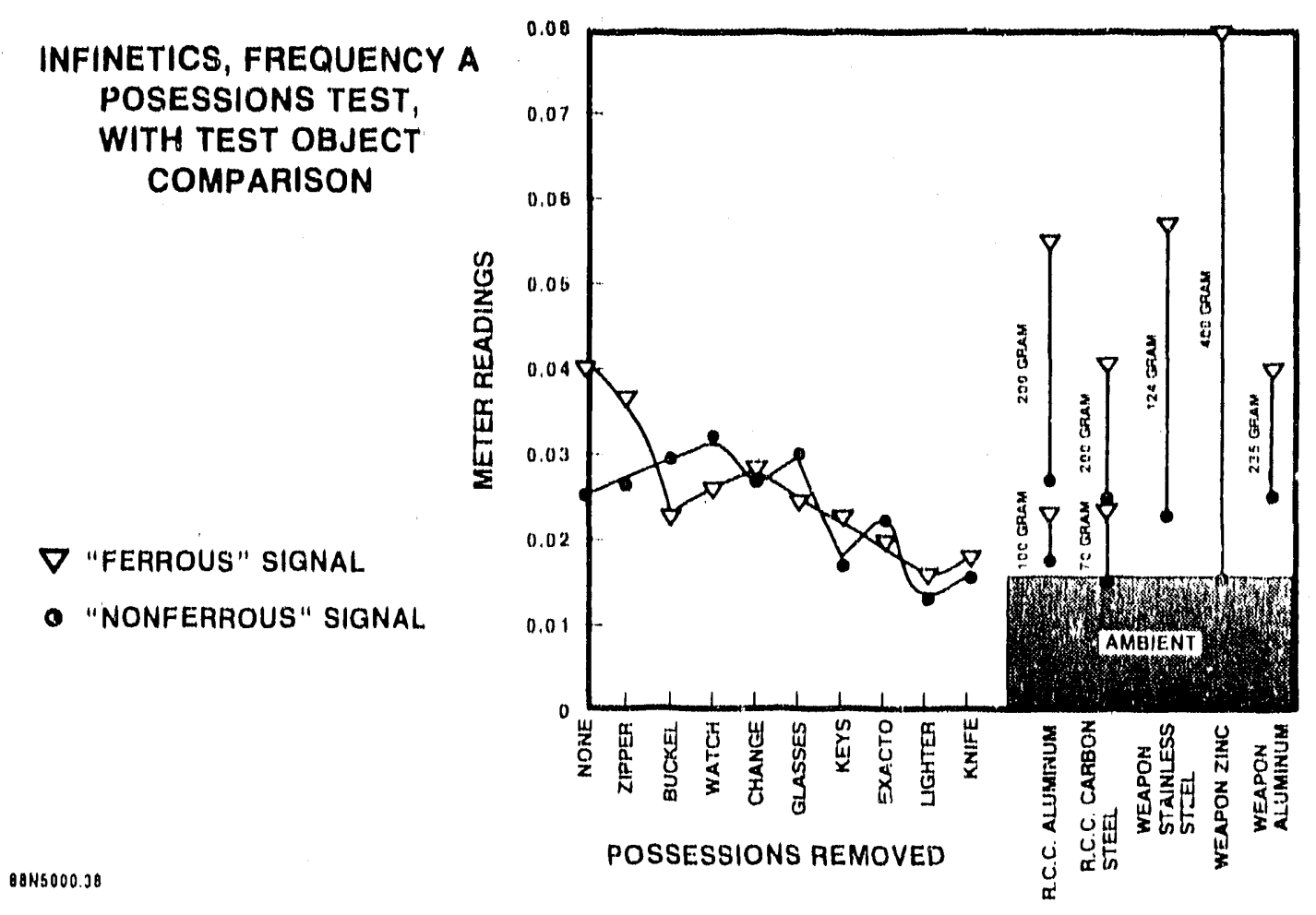

Figure $6-1$

\section{DEL NORTE PORTABLE BELT BUCKLE TEST}

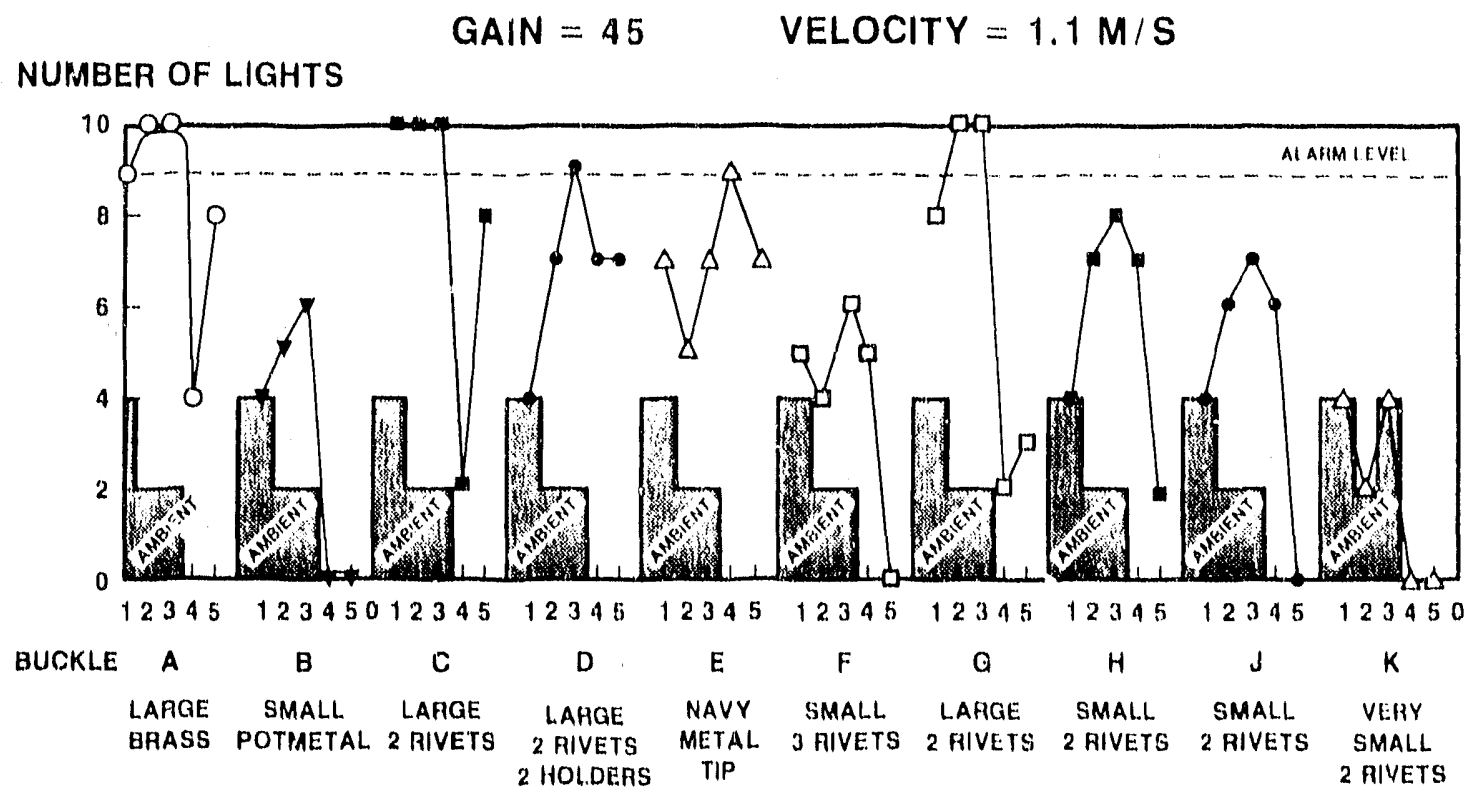

O8N5000.39

PROGRAM NUMBER

F'igure $6-2$ 


\begin{tabular}{|c|c|c|c|c|c|c|c|c|}
\hline & & & & $\begin{array}{l}\text { SCRIMIN } \\
\text { OUR GU } \\
\text { ETEOTOR }\end{array}$ & $\begin{array}{l}\text { TION TES } \\
\text { V SET-UP } \\
\text { IPROGRAN }\end{array}$ & & & \\
\hline TEST & $\begin{array}{l}\text { HS2S } \\
\text { HISEN }\end{array}$ & $\mathrm{AT}_{3}$ & $\stackrel{A T}{A T}$ & METOA 118 & METOH 118 & $\underset{O 0}{\text { METOR }} 120$ & ME TOR 120 & $\begin{array}{c}\text { INFINETICS } \\
280 \mathrm{HZ}\end{array}$ \\
\hline OBJECT & & & & & & & & \\
\hline KNIFE & A & $A$ & $A$ & A & A & A & A & $A$ \\
\hline LIGHTEF & A & A & $P$ & A & A & A & A & $A$ \\
\hline$X$-ACTO & A & $P$ & $P$ & $P$ & $P$ & A & A & A \\
\hline KEYS & A & $P$ & $P$ & $P$ & $P$ & $p$ & A & A \\
\hline WATCH & A & $P$ & $P$ & $P$ & $P$ & $P$ & $p$ & $A$ \\
\hline CHANGE & $P$ & $P$ & $P$ & $P$ & $P$ & $P$ & $P$ & $P$ \\
\hline BUCKLE & $P$ & $P$ & $P$ & $P$ & $P$ & $P$ & $P$ & $P$ \\
\hline & & & & $\begin{array}{c}A . \\
P .\end{array}$ & $\begin{array}{l}\text { ARM } \\
\text { ASS }\end{array}$ & & & \\
\hline
\end{tabular}

Figure 7 
METOR 118 PROGRAMMING GUIDE.

\begin{tabular}{|c|c|c|c|c|c|c|c|c|c|c|}
\hline \multicolumn{2}{|c|}{ Settings } & \multicolumn{7}{|c|}{ Detection parameters } & \multirow{3}{*}{$\begin{array}{l}\text { Noise } \\
\text { attenu- } \\
\text { ation }\end{array}$} & \multirow{3}{*}{$\begin{array}{l}\text { Typical } \\
\text { use }\end{array}$} \\
\hline $\begin{array}{l}\text { Pro- } \\
\text { gramine }\end{array}$ & Switch setting & \multicolumn{3}{|c|}{ Sensitivity } & \multicolumn{2}{|c|}{$\begin{array}{l}\text { Discrimt- } \\
\text { nation }\end{array}$} & \multirow{2}{*}{\multicolumn{2}{|c|}{\begin{tabular}{|l|}
$\begin{array}{l}\text { object } \\
\text { speed }\end{array}$ \\
norm fast \\
\end{tabular}}} & & \\
\hline & & high & norm & TOW & high & Tow & & & & \\
\hline 8 & IL & $x$ & & & & & & $x$ & & Sma 11 ttems \\
\hline 0 & 10[ & $x$ & & & & & $x$ & & & less stee 1 \\
\hline 9 & & $x$ & & & & & & $x$ & & \\
\hline 1 & 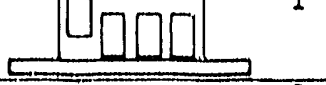 & $x$ & & & & & $x$ & & $x$ & \\
\hline 3 & 도 & & $x$ & & & $x$ & $x$ & & $x$ & Adjustable \\
\hline 2 & & & $x$ & & & $x$ & $x$ & & $x$ & small tools \\
\hline 10 & & & $x$ & & & $x$ & & $x$ & & coins and \\
\hline 12 & & & $x$ & & & $x$ & & $x$ & & \\
\hline 4 & 政 & & $x$ & & & $x$ & $x$ & & $x$ & \\
\hline 11 & 드 & & $x$ & & & $x$ & & $x$ & & \\
\hline 5 & & & & $x$ & & $x$ & $x$ & & $x$ & Large hand \\
\hline 13 & & & & $x$ & & $x$ & & $x$ & & \\
\hline 6 & $\underline{I}$ & & & $x$ & $x$ & & $x$ & & $x$ & \\
\hline 14 & $\square^{000}$ & & & $x$ & $x$ & & & $x$ & & \\
\hline 15 & 0000 & & & $x$ & $x$ & & & $x$ & & \\
\hline 7 & {$\left[00_{0}\right.$} & & & $x$ & $x$ & & $x$ & & $x$ & \\
\hline
\end{tabular}

Appendix A 


\section{SENTRIE ${ }^{\circledR}$ A T \\ ADVANCED TECHNOLOGY}

Program Definitions

PROGRAM 1

PROGRAM 2

PROGRAM 3

PROGRAM 4

PROGRAM 5

\section{General Handgun Screening Program}

This program will provide detection of a broad range of handguns while providing good discrimination against pocket clutter. Under most circumstances can be adjusted to detect small stainless steel weapons and weapons made of most common alloys.

\section{Ferrous Weapons Program}

This program will defect ferrous metal weapons of approximately $.25 \mathrm{cal}$ and larger. It will not detect most stainless steel items including weapons. It has better discrimination than Program 1. Very strong in detection of alloy weapons.

\section{Large Stainless Handgun Program}

This program can be adjusted to detect stainless steel handguns of $.25 \mathrm{cal}$ and larger with good detection of ferrous steel and alloy weapons. It has less discrimination than Programs 1 and 2.

Small Stainless Steel Handgun Program

This program can be adjusted to detect $.22 \mathrm{cal}$ stainless steel handguns with good discrimination. Some exotic materials of which handguns are made are difficult to detect with this program. It offers less discrimination than Programs 1 thru 3.

\section{High Sensitivity Programs}

These programs are designed for use in screening for metal objects where little or no tolerance for metal pocket clutter is allowed. People being screened with these programs will have to remove any metal object that is larger than the threat object used to set up the machine. For assistance in choosing one of the programs for a particular use, contact the Customer Service Department. 

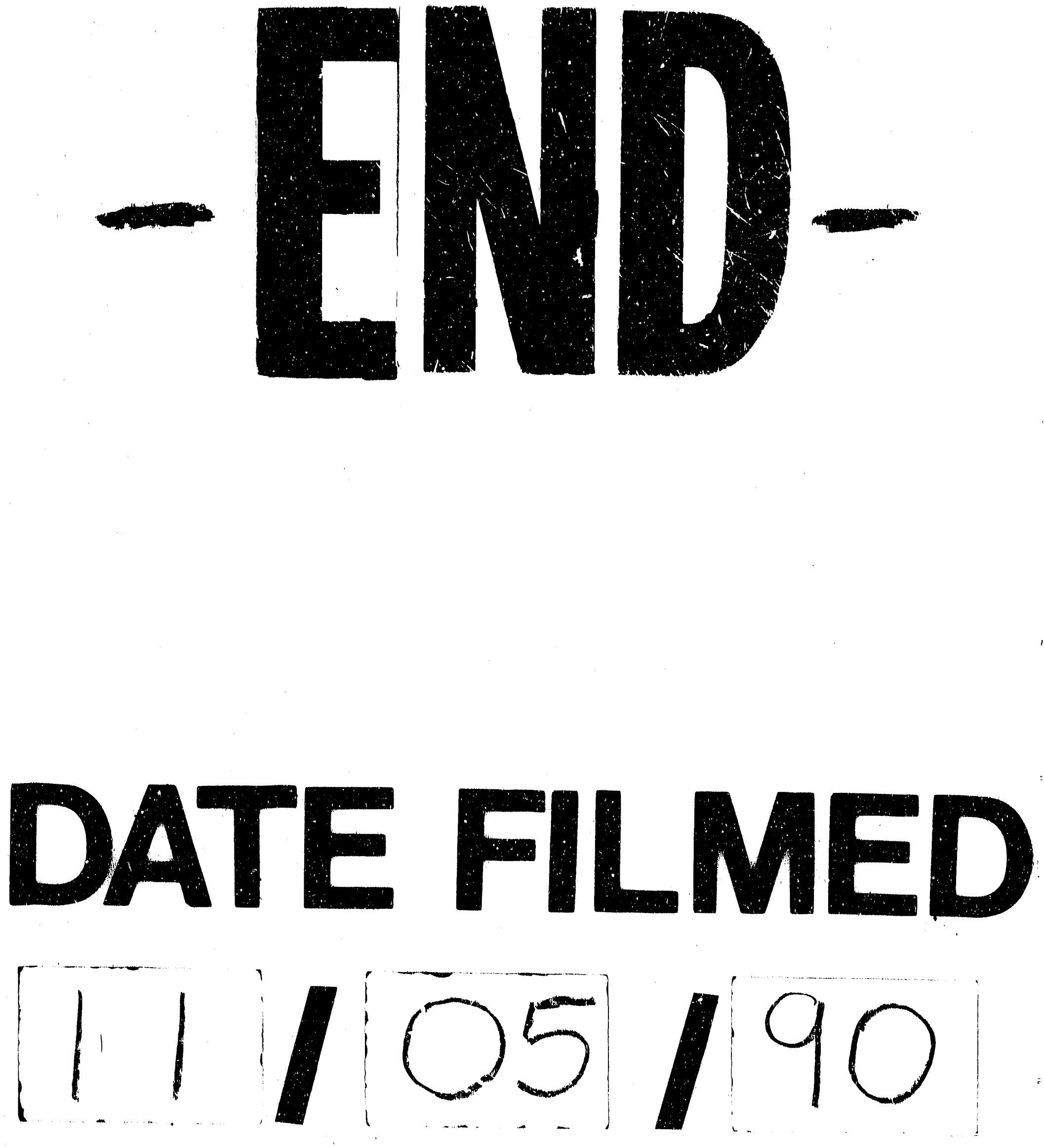